\title{
ESTRUCTURA Y COMPOSICIÓN FLORÍSTICA DE LA UEGETACIÓN DEL CORREDOR BIOLÓGICO ENTRE LOS PARQUES NACIONALES NATURALES PURACÉ Y CUEUA DE LOS GUÁCHAROS'
}

Palabras clave: Sucesión vegetal, diversidad, estructura de la vegetación, bosque andino, bosque secundario, corredor biológico, Huila, Colombia.

Key words: Plant succession, diversity, vegetation structure, andean forest, secondary forest, biological corridor, Huila, Colombia.

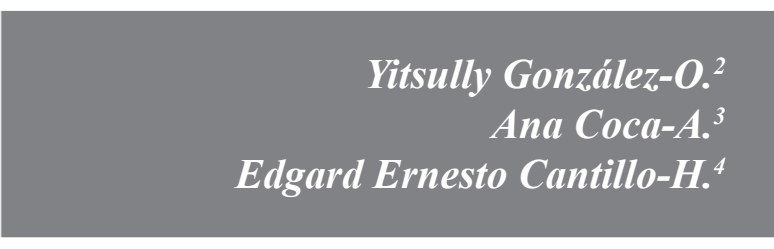

Para las asociaciones los valores de área basal por especie fueron similares. Para las comunidades, se presentaron los valores más altos con 7.3 y $4.6 \mathrm{~m}^{2}$, en la comunidad de Quercus humboldtii y Wettinia fascicularis. El promedio de alturas obtenido para las asociaciones fue de $13 \mathrm{~m}$, con valores de 10 y $15 \mathrm{~m}$. Para las comunidades, el promedio obtenido fue de $13 \mathrm{~m}$, con variaciones entre 7 y $17 \mathrm{~m}$. El estrato dominante en ambos casos fue el arbóreo inferior.

Los índices de importancia muestran que para todas las unidades a excepción de la Comunidad de Quercus humboldtii y Wettinia fascicularis, existe una representatividad equitativa de las especies dentro de cada unidad. Las familias mejor representadas en número de especies son Lauraceae, Rubiaceae y Melastomataceae.

Para las asociaciones los valores de área basal por especie fueron similares. Para las comunidades, se presentaron los valores más altos tación de la comunidad de Baccharis nitida y Saurauia pulchra.

\footnotetext{
Estudio denominado caracterización florístico estructural de la vegetación del corredor biológico entre los PNN Puracé y Cueva de los Guácharos (2007) realizado mediante el financiamiento de la Corporación Autoónoma Regionaldel Alto Magdalena CAM.

Ingeniera Forestal. Asistente de investigación, Universidad Distrital "Francisco José de Caldas". E-mail: yitsully@gmail.com Ingeniera Forestal. Asistente de investigación, Universidad Distrital "Francisco José de Caldas". E-mail: anitakro07@hotmail.com

Profesor de Ecología. Proyecto curricular de Ingeniería Forestal. Universidad Distrital "Francisco José de Caldas". E-mail: ecantillo@udistrital.edu.co
} 
con 7.34 y $4.6 \mathrm{~m}^{2}$, en la comunidad de Quercus humboldtii y Wettinia fascicularis. El promedio de alturas obtenido para las asociaciones fue de $13 \mathrm{~m}$, con valores de 10 y $15 \mathrm{~m}$. Para las comunidades, el promedio obtenido fue de $13 \mathrm{~m}$, con variaciones entre 7 y $17 \mathrm{~m}$. El estrato dominante en ambos casos fue el arbóreo inferior.

Los índices de importancia muestran que para todas las unidades a excepción de la Comunidad de Quercus humboldtii y Wettinia fascicularis, existe una representatividad equitativa de las especies dentro de cada unidad. Las familias mejor representadas en número de especies son Lauraceae, Rubiaceae y Melastomataceae.

\section{ABSTRACT}

The floristic composition and structure of disturbed and non disturbed vegetation at the biological corridor located among the National Natural Parks Puracé, Cueva de los Guácharos was studied based on 16 plots in three localities of the Huila Department, Colombia, between 1950 and $2450 \mathrm{~m}$. A total of 1.5 ha was sampled.

The Cyatheo - Cecropion angustifoliae alliance was defined. It includes the associations Ladenbergio macrocarpae - Elaeagietum myrianthae and Guettardo hirsutae - Hedyosmetum translucidi. At the less disturbed areas the communities Helicostylis tovarensis - Alfaroa williamsii, Quercus humboldtii - Wettinia fascicularis and Weinmannia pubescens - Clusia dixonii were found. The community $\mathrm{Bac}$ charis nitida and Saurauia pulchra was found in the most disturbed areas.

The basal area value per species was similar for all the associations. The community Quercus humboldtii and Wettinia fascicularis showed the highest basal area value, 7.3 and $4.6 \mathrm{~m} 2$. Regarding forest tall, an average of $11 \mathrm{~m}$ was found in the associations, with values from 10 to $15 \mathrm{~m}$. An average of $13 \mathrm{~m}$ was found in the communities, with variations from 7 to $17 \mathrm{~m}$. The dominant stratum in both cases was the arboreal inferior.

The importance indexes show an equal representativeness of the species inside each unit, with the exception of the Quercus humboldtii and Wettinia fascicularis community. The best represented families regarding their species number are Lauraceae, Rubiaceae and Melastomataceae.

\section{INTRODUCCIÓN}

Los corredores biológicos definidos como mecanismo para la conservación, son áreas que a través de su ordenamiento permiten la conexión entre dos o más áreas protegidas con el fin de lograr el intercambio genético y mantener o aumentar la riqueza y diversidad (modificado de CCAD-PNUD/GEF, 2002).

Dependiendo de las características ecológicas y sociales del área, en los corredores biológicos se pueden llevar a cabo actividades netamente protectoras o de producción sostenible. En el caso del corredor biológico entre los $\mathrm{PNN} \mathrm{Pu}-$ racé, Cueva de los Guácharos, se han destinado algunas áreas para la producción mediante arreglos forestales, mientras que otras áreas sirven para la protección de los recursos naturales.

El estudio se enmarcó dentro del componente de reforestación y protección al medio ambiente; de esta manera se realizó una caracterización florística y estructural de la vegetación de las áreas boscosas y de las zonas intervenidas que integran el corredor biológico con el fin de conocer las especies, su arreglo espacial, su diversidad y así determinar el manejo apropiado de acuerdo a sus posibilidades de uso.

De acuerdo con las observaciones realizadas, la conservación de los bosques depende del grado de accesibilidad, su cercanía a las viviendas

Revista Colombia Forestal Vol. 10 No. 20 - Diciembre 2007 
y en el caso de áreas privadas del compromiso de protección por parte de los propietarios. La mayoría de los bosques bien conservados se encontraron en sitios con pendientes muy escarpadas y a grandes distancias, en muchos casos se observaron áreas que habían sido aprovechadas intensamente. En la actualidad se presentan aprovechamientos sectorizados para fines domésticos que han sido permitidos por la Corporación Autónoma Regional del Alto Magdalena (CAM).

Aunque la zona de estudio fue catalogada como una de las más diversas del macizo colombiano al ser declarada como reserva de la biosfera en 1979, en la actualidad son pocos los estudios realizados. Entre las investigaciones que se conocen se destacan las de Cleef (1972), Lozano (1979) y Mahecha (1999) que fueron elaboradas para contribuir al conocimiento de la flora de los bosques mediante la elaboración de catálogos. Igualmente los trabajos ecológicos son reducidos, se encuentra el de Bernal (1976), quien realizó un estudio donde presenta la composición florística y estructural de los bosques del municipio de Acevedo; Duque (1987), quien elaboró un estudio de las comunidades vegetales del PNN Puracé; Rangel \& Franco (1985), con los registros y observaciones fitoecológicas en dos transectos realizados desde la Plata (Huila) hasta el Puracé, que luego sería complementada con la caracterización de la vegetación realizada por Rangel \& Lozano (1986) a lo largo de un transecto desde La Plata (Huila) hasta el Volcán del Puracé. Duque \& Rangel (1989), realizaron un análisis fitosociológico de la vegetación del páramo del PNN Puracé.

En la región Andina se han realizado diferentes estudios ecológicos como las contribuciones de Rangel (1995), quien efectuó un estudio de diversidad de las familias, géneros y especies de la vegetación en el Parque los Nevados; Rangel \& Garzón (1994), con la caracteri- zación estructural, dinámica y diversidad de la vegetación en el Parque Regional Natural Ucumarí; Rangel et al. (1982) quienes hicieron una descripción de las regiones a lo largo de un transecto realizado en el Tayrona y Pozos Colorados entre 0 y 4100 msnm y Rangel et al. (2003) con la clasificación sintaxonómica de los bosques subandinos del transecto Parque de los Nevados. Entre otros estudios acerca de los cambios de la vegetación se encuentran el de Rojas (1984), quien registró observaciones sobre la dinámica sucesional durante ocho años en áreas que habían sido destinadas a la ganadería extensiva y Bello \& Kattib (1994), que determinaron el proceso de sucesión secundaria en la franja subandina después de la quema de algunas de las unidades de vegetación.

\section{ÁREA DE ESTUDIO}

El corredor biológico entre los PNN Puracé y Cueva de los Guácharos se encuentra ubicado entre los $5^{\circ} 57^{\prime} 19^{\prime \prime}$ a $6^{\circ} 38^{\prime} 17.6^{\prime \prime} \mathrm{N}$ y $72^{\circ} 14^{\prime}$ $38^{\prime}$ " a $73^{\circ} 2$ ' $20^{\prime \prime} \mathrm{W}$, al sur del departamento del Huila, Colombia, en una superficie calculada de 84465 ha (Figura 1). Comprende áreas de los municipios de San Agustín, Pitalito, Acevedo y Palestina (Sánchez 2003). Los levantamientos se ubicaron entre los 1955 y 2443 msnm.

De acuerdo con las estaciones de San Agustín, Pitalito, Suaza y Puracé, se presenta a lo largo del corredor un régimen de precipitación bimodal tetraestacional (Figura 2) con valores promedio anuales de 1201,9 mm en la estación de Suaza a 1402,3 mm en la estación de San Agustín. El pico de mayor precipitación se encuentra en mayo para las estaciones de Pitalito y Suaza y junio en la estación de San Agustín.

Se presenta un régimen isotérmico con variaciones promedio de $1.5^{\circ} \mathrm{C}$ a lo largo del año. En las estaciones, los valores medios de temperatura oscilan entre los $11.06{ }^{\circ} \mathrm{C}$ y $22.42^{\circ} \mathrm{C}$, en San Agustín y Acevedo respectivamente. Los 


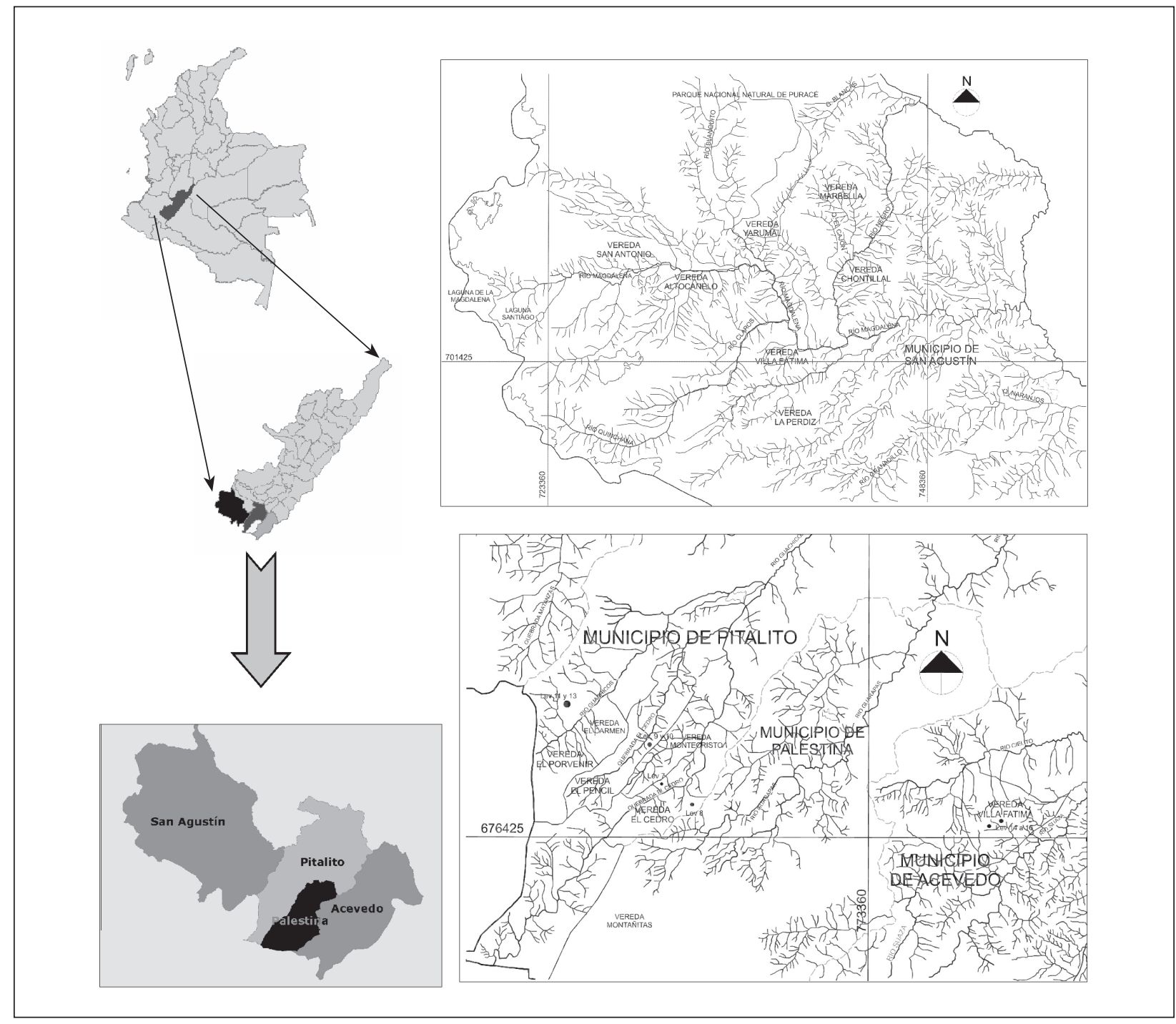

Figura 1. Área objeto de estudio. Ubicación de las veredas visitadas en el corredor biológico entre los PNN Puracé y Cueva de los Guácharos. Izquierda: Vista general del corredor biológico. Derecho - Superior: municipio de San Agustín. Inferior: municipio de Pitalito y Acevedo (Modificado del mapa de trabajo del proyecto corredor biológico).

promedios mínimos de temperatura se encuentran entre $2.5^{\circ} \mathrm{C} \mathrm{y} 11.6^{\circ} \mathrm{C}$, en las mismas estaciones. En González et al. (2008) se encuentra mayor información climática de la región.

El área del corredor biológico según la clasificación de Cuatrecasas (1958), pertenece a la franja de Selva Subandina y Andina. De acuerdo con la clasificación climática de Holdridge (1987), las estaciones de Pitalito, San Agustín y Suaza pertenecen a la franja de bosque húmedo premontano (bh-PM), mientras que la estación
Puracé se define como bosque húmedo montano bajo (bh-MB). De acuerdo a Fernández (1989), el material parental predominante de la región de Acevedo es proveniente de rocas ígneas, principalmente granitos moscovíticos y andesitas ortósicas, además de rocas sedimentarias como areniscas, arcillas rojas y grises, conglomerados y aglomerados. El material parental en el municipio de Pitalito, está compuesto principalmente por rocas sedimentarias y una gruesa capa de arenisca roja, sobre la cual descansa una capa de arcilla. Los suelos del co- 


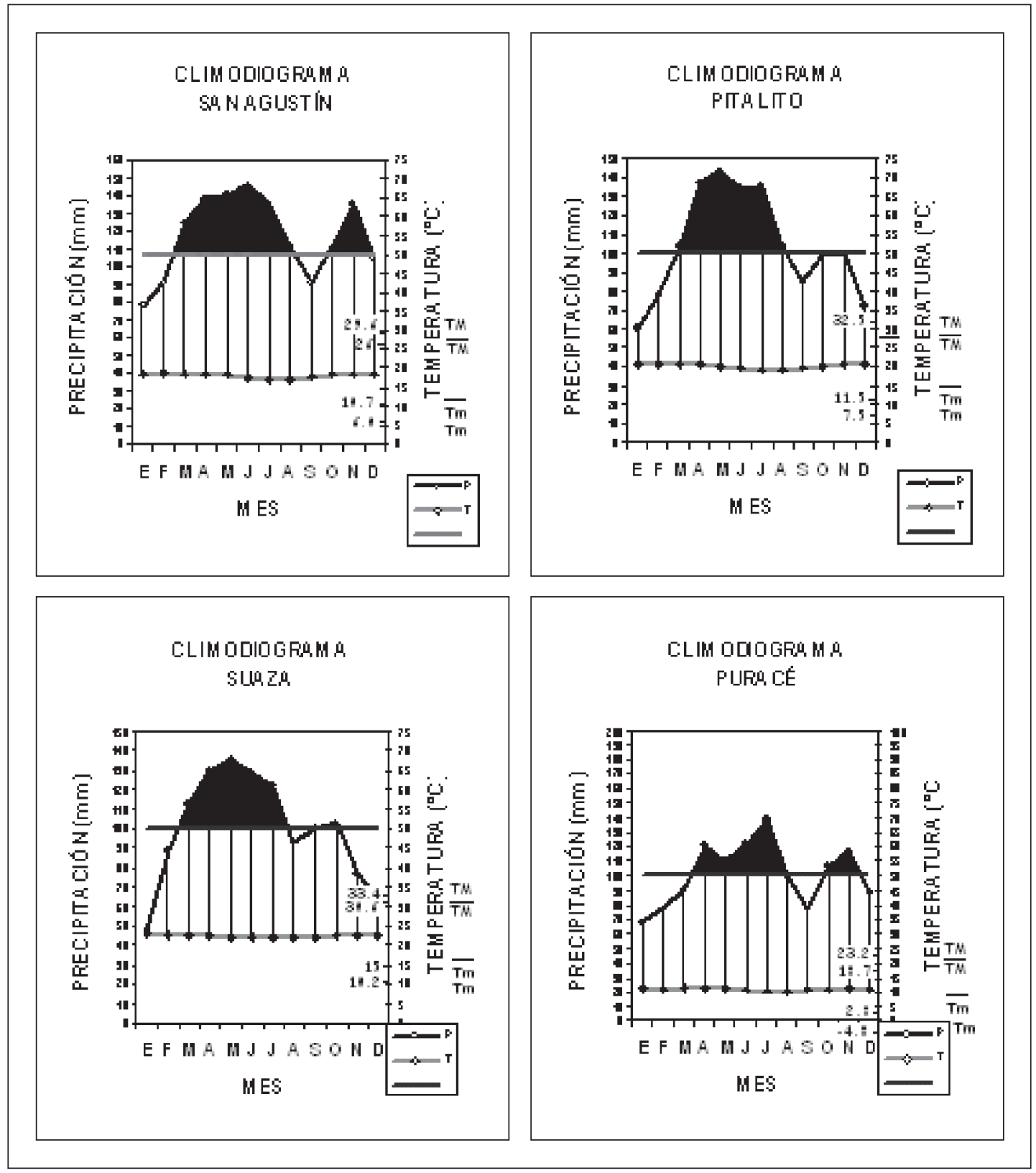

Figura 2. Climodiogramas para las estaciones de San Agustín, Pitalito, Suaza y Puracé (Tomado de Coca \& González 2006).

rredor biológico poseen texturas desde Francas hasta Areno Francosas, $\mathrm{pH}$ promedios de 3.8 a 5.3 , bajos contenidos de fósforo (0-3.79 ppm), contenidos de materia orgánica entre $1.5 \%$ y $5.3 \%$ y CIC entre 22.6 y $37.2 \mathrm{meq} / 100 \mathrm{~g}$.

Los levantamientos realizados en el municipio de San Agustín, muestran que la textura predo- minante es Areno-Francosa, $\mathrm{pH}$ entre 4.5 y 5 , contenidos de fósforo de $3.7 \mathrm{ppm}$ en promedio, porcentaje de materia orgánica de $5.2 \%$ en los primeros $30 \mathrm{~cm}$ y $3.2 \%$ en los $60 \mathrm{~cm}$, y una CIC de 30 a 38 meq/100g.

En el municipio de Pitalito, los suelos poseen una textura Franco-Arenosa, aunque también se 
encontraron texturas Francas y Franco Arcillo Arenosas, $\mathrm{pH}$ entre 5 y 5.3, valores de fósforo entre 2 y 3.6, contenidos de materia orgánica entre $3.5 \%$ en los primeros $30 \mathrm{~cm}$ y $1.7 \%$ a $60 \mathrm{~cm}$. Los valores de CIC son muy uniformes hasta los $60 \mathrm{~cm}$ con valores de 22 a $24 \mathrm{meq} / 100 \mathrm{~g}$.

En el municipio de Acevedo, se encontró que la textura es Franco Arenosa, pH muy ácidos entre 3.8 a 4.6, valores muy bajos de fósforo, desde nulos hasta $0.65 \mathrm{ppm}$ en promedio, porcentajes de materia orgánica entre $5.3 \%$ en los primeros $30 \mathrm{~cm}$ y $2.5 \%$ a $60 \mathrm{~cm}$. Los valores promedios de CIC se encuentran entre 29.6 y $33.5 \mathrm{meq} / 100 \mathrm{~g}$.

\section{MATERIALES Y MÉTODOS}

Los sitios a muestrear se determinaron con la ayuda de imágenes de satélite de propiedad de la Corporación Autónoma Regional del Alto Magdalena (CAM). Fueron escogidos los bosques con el mejor estado de conservación y de mayor extensión relativa en cada uno de los municipios. Las veredas visitadas se escogieron de acuerdo al grado de accesibilidad de cada una. Para el análisis climático se calcularon los índices termopluviométricos de Caldas \& Lang, climodiogramas y balances hídricos. El mapa de Isohietas se elaboró con todas las estaciones cercanas al área de estudio y con ayuda del programa Surfer®.

Se elaboraron parcelas de $1000 \mathrm{~m}^{2}(10 \times 100$ $\mathrm{m})$. En cada una se estructuraron cuatro subparcelas de 5 x $5 \mathrm{~m}$ para obtener la información referente a latizales $(2.5 \mathrm{~cm}<\mathrm{DAP}<10 \mathrm{~cm}$ y con alturas $\geq 1.5 \mathrm{~m}$ ) a su vez dentro de cada una se realizó una subparcela de $2 \times 2 \mathrm{~m}$ para el conteo de brinzales (individuos con alturas $<1.5 \mathrm{~m}$ ).

Para la toma de información en las áreas intervenidas se diseñaron levantamientos desde $500 \mathrm{~m}^{2}$ hasta $1000 \mathrm{~m}^{2}$ dependiendo de la extensión de los bosques. Las subparcelas para latizales y brinzales se realizaron a manera de fajas a lo largo de la parcela, cada $25 \mathrm{~m}$. Para los latizales se establecieron cuatro fajas de 10 $\mathrm{x} 5 \mathrm{~m}$ y para los brinzales otras cuatro de 10 × 2 $\mathrm{m}$, de esta manera se obtuvo información adicional sobre las especies arbustivas, las cuales son representativas de sitios intervenidos.

Los datos tomados en campo para cada árbol mayor a $10 \mathrm{~cm}$ de DAP (fustales) y latizales fueron: nombre vulgar, número consecutivo $\mathrm{y}$ de colección, ubicación en coordenadas ( $\mathrm{x}$, y) dentro de la parcela, altura total, altura comercial, CAP (Circunferencia a la altura del pecho) diámetros de copa, así como defectos estructurales y fitosanitarios de cada árbol. Para los brinzales se consignó en los registros su abundancia por especie. Igualmente se tomaron coordenadas, altitud, pendiente y azimuth de cada levantamiento realizado.

La fase de colección, tratamiento e identificación de las muestras se encuentra explicado ampliamente en González et al. (2008) donde se presenta el catálogo general de las especies identificadas.

Luego de obtener la información de cada especie, se actualizaron las bases de datos y en base a su presencia y cobertura, se definieron las unidades sintaxonómicas mediante el uso del programa PC - ORD con su aplicación automatizada TWINSPAN. También se obtuvo la información de las especies exclusivas y electivas de cada unidad (Anexo 2).

La fase de suelos se dividió en dos, en una primera instancia se tomaron las muestras de barrenadas en zigzag de acuerdo a la metodología usada por Cantillo et al. (2005) donde cada levantamiento se dividió en dos subparcelas de 10 x $50 \mathrm{~m}$, y se obtuvieron dos grandes muestras de barrenadas a $30 \mathrm{~cm}$ y $60 \mathrm{~cm}$ de profundidad, obteniendo cuatro muestras por levantamiento. 
Se realizaron 16 calicatas, donde se describieron cada uno de los horizontes encontrados. Se tomaron datos de color con la ayuda de la tabla Munsell ${ }^{\circledR}$, textura, consistencia a capacidad de campo y en húmedo, entre otras variables que sólo se pueden obtener en campo como estructura, porosidad, cantidad y grosor de raíces, presencia de cutanes y formaciones especiales.

A su vez, se tomaron datos relacionados con el paisaje, forma y disposición del sitio muestreado, material parental de la zona y de uso actual del suelo.

El análisis de las 64 muestras de suelos, contienen los resultados de textura determinada por el método de Bouyoucos, carbono orgánico (método de Walckley - Black), fósforo (Bray y Kurtz), acidez intercambiable (titulación con hidróxido de sodio para $\mathrm{pH}>5,4$ ), C.H.\% (relación masa de agua, masa de sólidos), Capacidad de Intercambio Catiónico (CIC) (extracción acetato de amonio), Bases intercambiables (acetato de amonio $1 \mathrm{~N}-\mathrm{ab}$ sorción atómica) y $\mathrm{pH}$.

\section{RESULTADOS}

\section{CARACTERIZACIÓN FLORÍSTICA}

En el análisis florístico, se definió la alianza Cyatheo - Cecropion angustifoliae que incluye las asociaciones Ladenbergio macrocarpae - Elaeagietum myrianthae y Guettardo hirsutae - Hedyosmetum translucidi. Igualmente se reseñaron las comunidades de Helicostylis tovarensis y Alfaroa williamsii, Quercus humboldtii y Wettinia fascicularis, Baccharis nitida y Saurauia pulchra. y la comunidad de Weinmannia pubescens y Clusia dixonii.

El número de levantamientos y altitud a la cual se encontraron cada una de las unidades sintaxonómicas, se puede observar en la tabla florística (Anexo 2).

\section{ALIANZA CYATHEO - CECROPION ANGUSTIFOLIAE}

Asociación tipo: Ladenbergio macrocarpae - Elaeagietum myrianthae

Anexo 1, Figuras 9 y 10.

Fisionomía: Bosques con un estrato arbóreo inferior con 59\% de cobertura. El estrato subarbóreo ocupa el 28\%. (Figura 9). El promedio de alturas es de 13m. (Figura 10).

Las especies más dominantes y abundantes en el estrato arbóreo inferior son Aniba robusta con 23 individuos, Elaeagia myriantha con 21 individuos y Cecropia angustifolia con 19 individuos.

Composición: Las especies características son Ladenbergia macrocarpa, Elaeagia myriantha, Nectandra globosa, Aniba robusta, y Weinmannia pubescens.

Diversidad: Se contabilizaron en total 445 individuos, distribuidos en 105 especies y 45 familias. El estrato de mayor riqueza (para ind. DAP $\geq 10 \mathrm{~cm}$ ) es el arbóreo inferior, con 195 individuos y 80 especies, seguido del estrato subarbóreo con 209 individuos y 64 especies. Las familias con mayor número de individuos son Lauraceae y Rubiaceae con 77 y 58 individuos respectivamente. También poseen el mayor número de especies con 17 y 12 especies cada una.

\section{Asociación Ladenbergio macrocarpae - Elaeagietum myrianthae Perfil: Figura 3.}

Levantamiento tipo: Lev. 3, vereda Yarumal. Anexo 1, Figuras 9 y 10.

Fisionomía: El estrato arbóreo inferior cubre el $48 \%$, le sigue el subarbóreo con el $28 \%$ de cobertura sobre el área total. (Figura 9). El promedio de alturas obtenido para la asociación 
fue de $15 \mathrm{~m}$, con variación entre 10 y $19 \mathrm{~m}$. (Figura 10).

En el estrato arbóreo inferior las especies dominantes y de mayor abundancia son Cecropia angustifolia y Elaeagia myriantha con 18 individuos y Aniba robusta con 17 individuos.

Composición: Las especies exclusivas y con altos valores de fidelidad son Vismia baccifera, Tapirira guianensis, Helicostylis tovarensis, Viburnum colombianum, Cinnamomum triplinerve y Alfaroa williamsii. Como especies electivas importantes se encuentran Cecropia angustifolia y Ladenbergia macrocarpa.

Diversidad: Se estimaron para la asociación 193 individuos, distribuidos en 54 especies por
0.1 ha. El estrato de mayor riqueza es el arbustivo, con 21 especies seguido del arbóreo inferior con 16 especies en 0.1 ha. Las familias más importantes son Lauraceae y Rubiaceae con 56 y 34 individuos y con 14 y ocho especies cada una.

\section{Asociación Guettardo hirsutae}

- Hedyosmetum translucidi.

Perfil: Figura 4.

Levantamiento tipo: Lev. 5 vereda

Los Alpes, Marbella.

Municipio de San Agustín

Anexo 1, figuras 9 y 10.

Fisionomía: El estrato arbóreo inferior cubre el 77\% del área, seguido por el estrato arbóreo superior con el 30\%. (Figura 9). El promedio

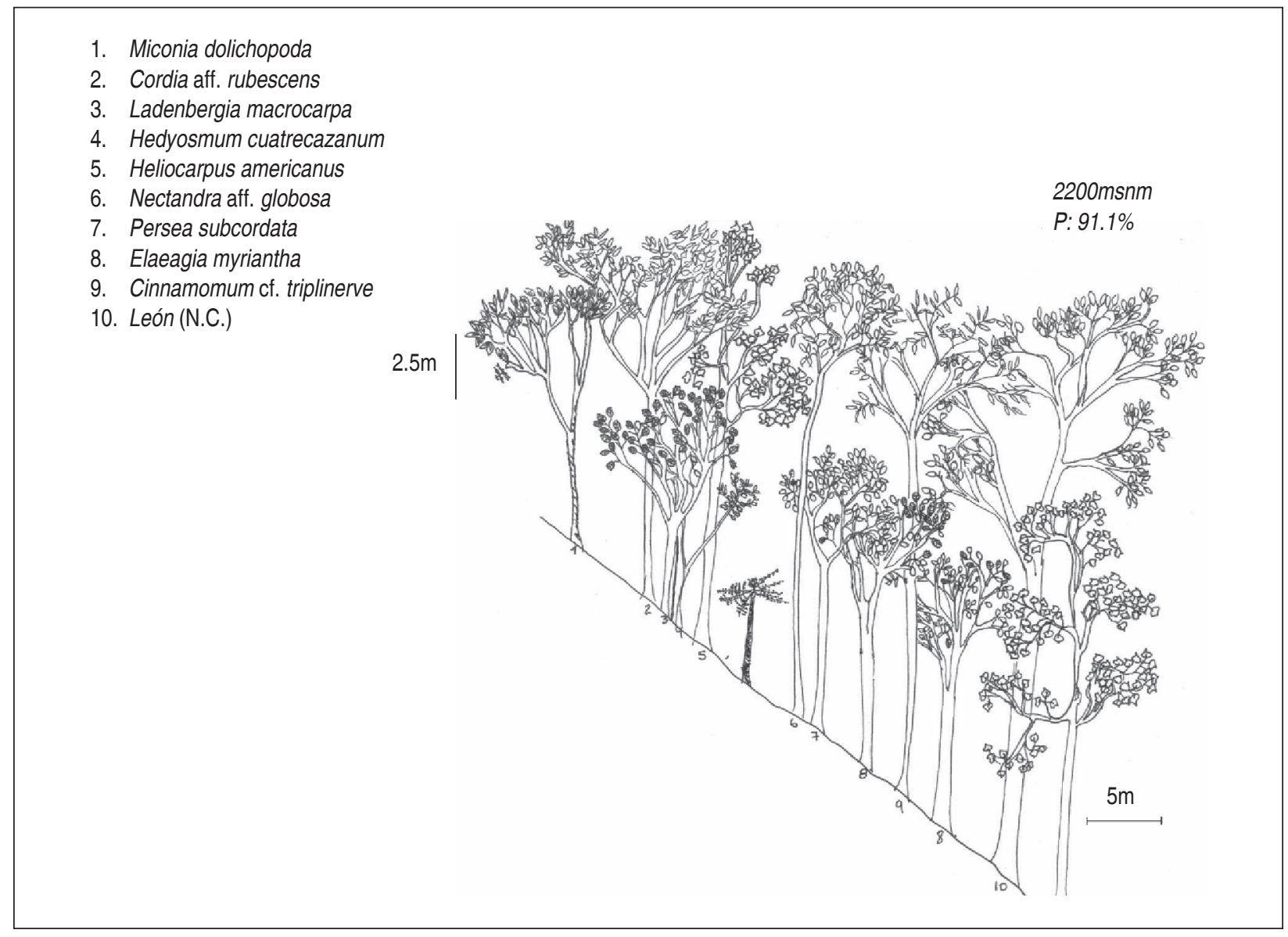

Figura 3. Perfil fisionómico florístico de la asociación Ladenbergio macrocarpae - Elaeagietum myrianthae. 
de alturas fue el más bajo registrado con $10 \mathrm{~m}$ en promedio. (Figura 10).

En el estrato arbóreo inferior Wettinia sp con 17 individuos y Hedyosmum translucidum con siete individuos poseen la mayor abundancia. En el arbóreo superior se encontró la especie León sp. (NC) la cual no pudo ser colectada debido a la altura de sus individuos.

Composición: Las especies exclusivas con altos valores de fidelidad son Guettarda hirsuta y Hedyosmum racemosum. En cuanto a especies electivas se presentan Hedyosmum translucidum, Morus insignis, Nectandra discolor, Spirotheca rhodostyla, entre otras encontradas en zonas con mayor intervención como $\mathrm{Bac}$ charis nitida y Montanoa quadrangularis.

Diversidad: Se encontraron 197 individuos y 59 especies por 0.1 ha, el cual es un valor alto debido a que la asociación se definió en las primeras etapas de sucesión. El estrato arbustivo, posee el mayor número de individuos, sin embargo el estrato herbáceo es el de mayor riqueza con los valores más altos de especies y familias. Las familias con mayor número de individuos son Arecaceae y Rubiaceae con 17 y nueve individuos cada una. La familia Rubiaceae es la de mayor riqueza, con cuatro especies.

Comunidad de Helicostylis tovarensis y Alfaroa williamsii

Perfil: Figura 5.

\section{Levantamiento tipo: Lev. 10 Vereda El Pencil.}

Anexo 1, Figuras 9 y 10.

Fisionomía: El estrato arbóreo inferior cubre el 98\% del área total, le sigue el estrato subarbóreo con el $26 \%$ de cobertura. (Figura 9). El promedio de alturas encontrado para la comunidad fue de $15 \mathrm{~m}$. (Figura 10).

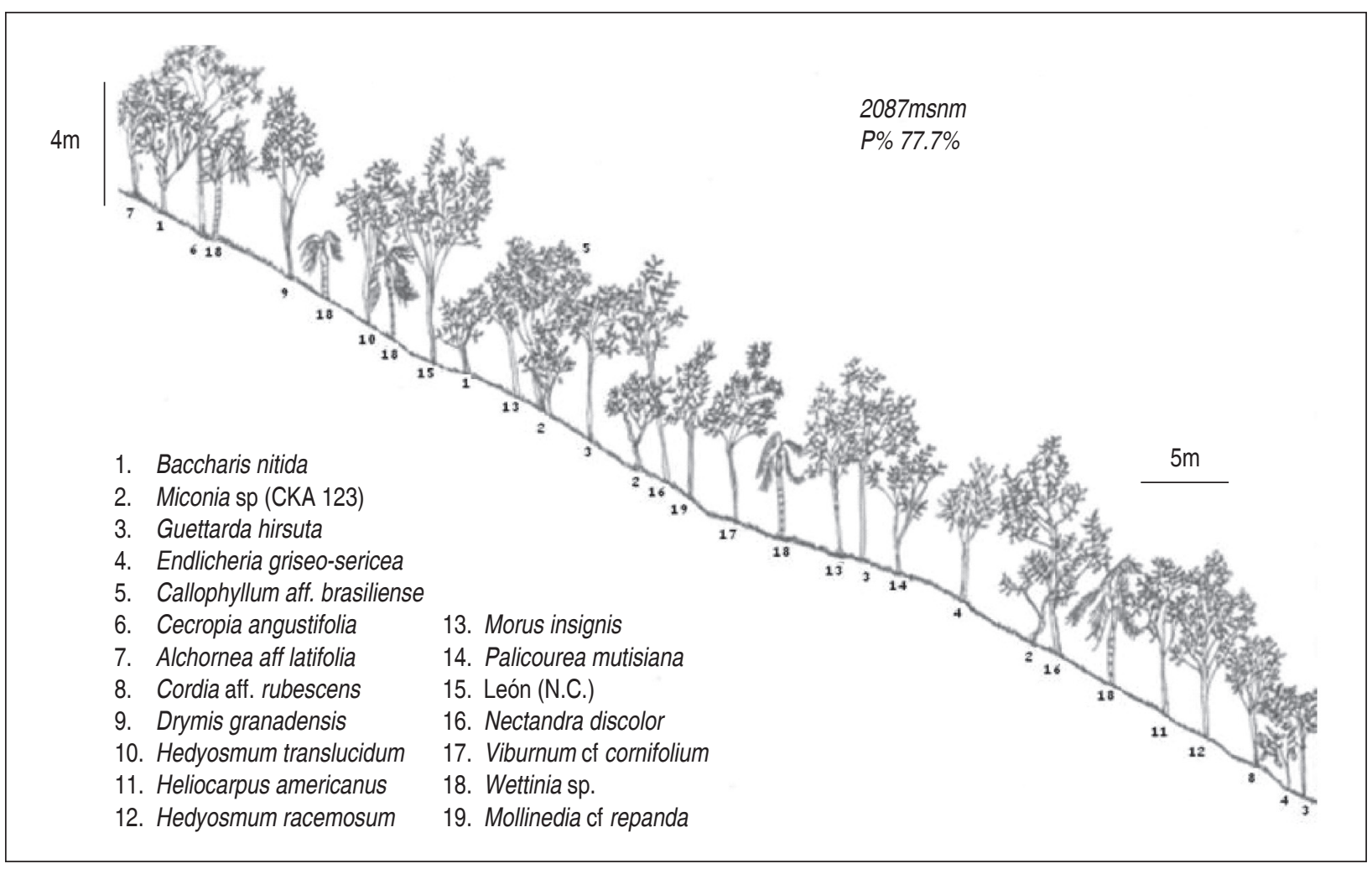

Figura 4. Perfil fisionómico florístico de la asociación Guettardo hirsutae - Hedyosmetum translucidi. 
En el estrato arbóreo inferior la especie de mayor abundancia es Endlicheria griseo - serícea con nueve individuos. Igualmente en el estrato subarbóreo Alfaroa williamsii posee nueve individuos. Hedyosmum cuatrecazanum y Helicostylis tovarensis con siete individuos cada una, son representativas del estrato subarbóreo.

Composición: Las especies exclusivas de esta comunidad son Helicostylis tovarensis, Spirotheca rhodostyla, Pouteria baehniana, Palicourea garciae, Prunus opaca, Hedyosmum cuatrecazanum y Cinnamomum triplinerve. En cuanto a especies electivas se presentan Endlicheria griseo-serícea, Alfaroa williamsii, $\mathrm{Ce}$ cropia angustifolia y Cyathea sp.
Diversidad: Para esta comunidad se encontraron en total 187 individuos distribuidos en 66 especies por 0.1 ha. La mayor riqueza de especies y familias se encontró en el estrato arbóreo inferior para el levantamiento 7 con 30 especies y 22 familias, mientras que para el levantamiento 10 se encontró en el estrato arbustivo con 26 especies y 15 familias. Las especies más representativas son Lauraceae y Asteraceae con 30 y 11 individuos respectivamente. La familia Lauraceae también posee la mayor riqueza con 13 especies.

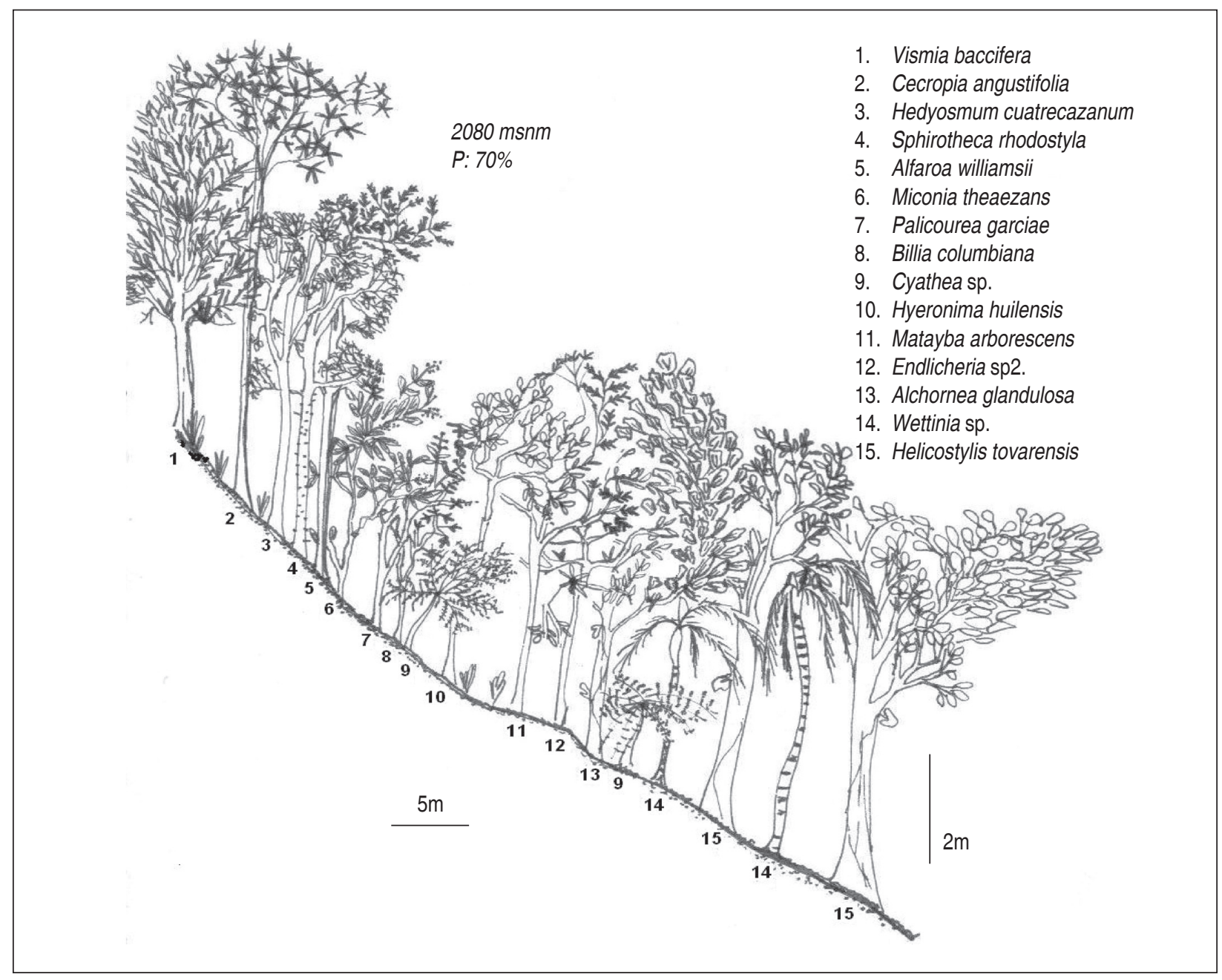

Figura 5. Perfil fisionómico florístico de la Comunidad de Helicostylis tovarensis y Alfaroa williamsii. 
Comunidad de Quercus humboldtii

y Wettinia fascicularis

Perfil: Figura 6

Levantamiento tipo: 15 , Vereda Villa Fátima.

\section{Anexo 1, Figuras 9 y 10.}

Fisionomía: El estrato arbóreo inferior cubre el $53 \%$ del área, seguido por el estrato subarbóreo con el $41 \%$. (Figura 9). El promedio de alturas para la comunidad fue de $12 \mathrm{~m}$. (Figura 10).

Las especies que tienen mayor abundancia son Quercus humboldtii con 20 individuos y Wettinia fascicularis con 64 individuos para la comunidad. El roble negro Colombobalanus excelsa posee 12 individuos. Se destaca la presencia de Aiphanes linearis, Dugandiodendron colombianum y Abarema killipii.
Composición: Las especies exclusivas más importantes para la comunidad son: Quercus humboldtii, Wettinia fascicularis, Colombobalanus excelsa, Abarema killipii, Blakea fissicalyx, Hedyosmum racemosum, Pouteria argenteum y $P$. torta, como especie electiva figura Dictyocaryum lamarckianum.

Diversidad: Se presentan 169 individuos y 40 especies por 0.1 ha. El estrato con mayor riqueza es el estrato arbustivo con un promedio de 26 especies. Las familias más representativas de la comunidad son Arecaceae y Fagaceae con 65 y 32 individuos cada una. Arecaceae y Lauraceae poseen cada una tres especies.

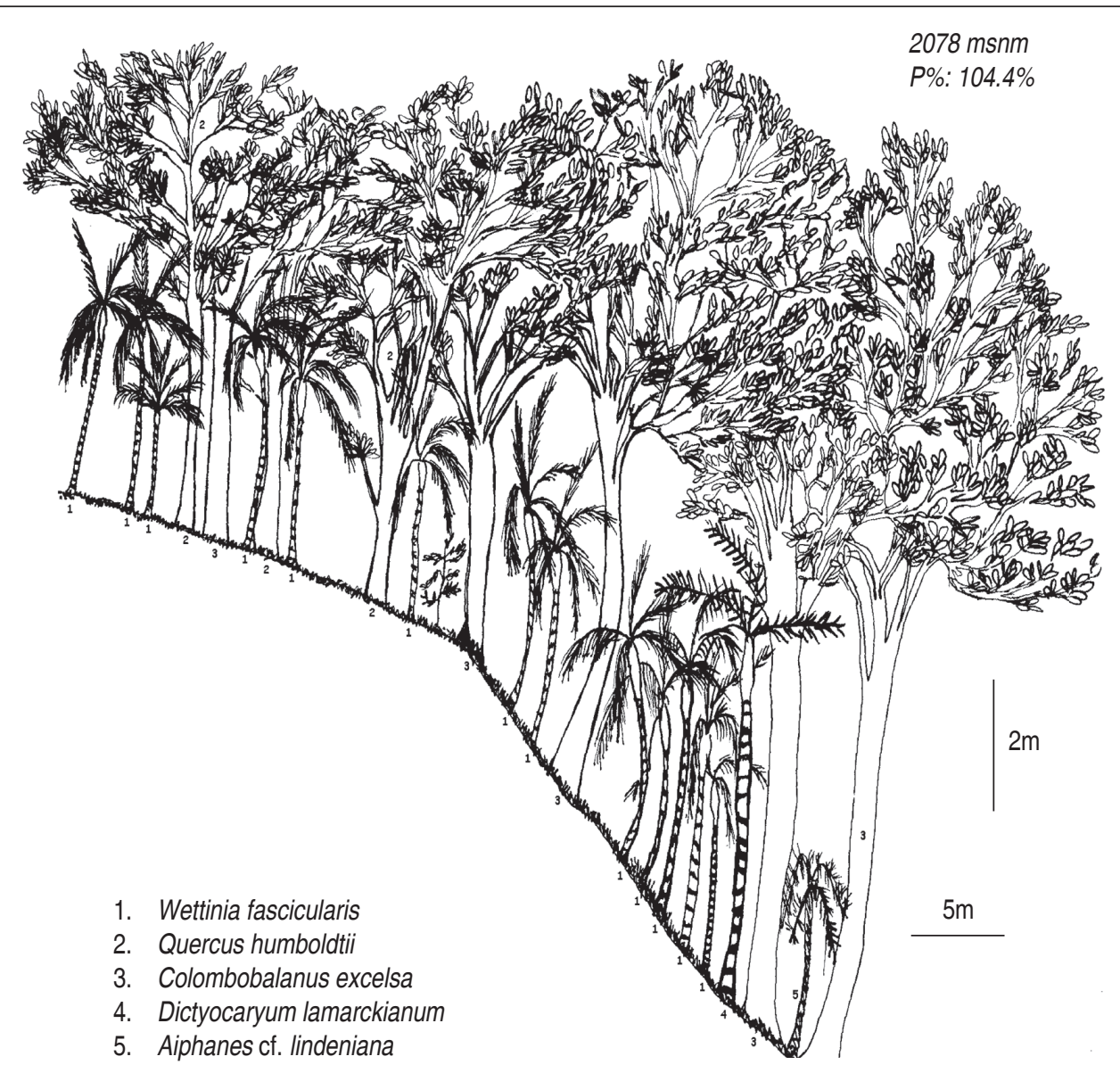

Figura 6. Perfil fisionómico florístico de la Comunidad de Quercus humboldtii y Wettinia fascicularis. 


\section{Comunidad de Baccharis nitida y Sauarauia pulchra \\ Perfil: Figura 7. \\ Levantamiento tipo: 8, Vereda EI Cedro. Anexo 1, Figuras 9 y 10.}

Fisionomía: El estrato con mayor cobertura es el subarbóreo, con 12\% del área (Figura 9). El promedio de alturas obtenido fue de $7 \mathrm{~m}$ (Figura 10).

Las especies con mayor abundancia en el estrato subarbóreo fueron Saurauia pulchra con diez individuos, Piper lanceaefolium var latifolium con nueve individuos y Baccharis niti$d a$ con seis individuos. También es importante resaltar la presencia de Alfaroa williamsii en casi todos los estratos.
Composición: Las especies exclusivas para la comunidad y que además obtuvieron los mayores valores de presencia y cobertura fueron Baccharis nitida, Saurauia pulchra, Rubus urticifolius, Piper lanceaefolium var latifolium y Austroeupatorium inulifolium.

Diversidad: El estrato rasante posee la mayor riqueza con 18 especies sin embargo en el levantamiento nueve se presenta la mayor riqueza en el estrato arbustivo con 26 especies. Las familias con mayor abundancia de individuos son Actinidiaceae y Piperaceae con diez y nueve individuos respectivamente. Las familias con mas número de especies fueron Solanaceae, Rubiaceae y Asteraceae. Se encontraron 126 individuos y 36 especies con DAP mayores a $10 \mathrm{~cm}$ en 0.1 ha.

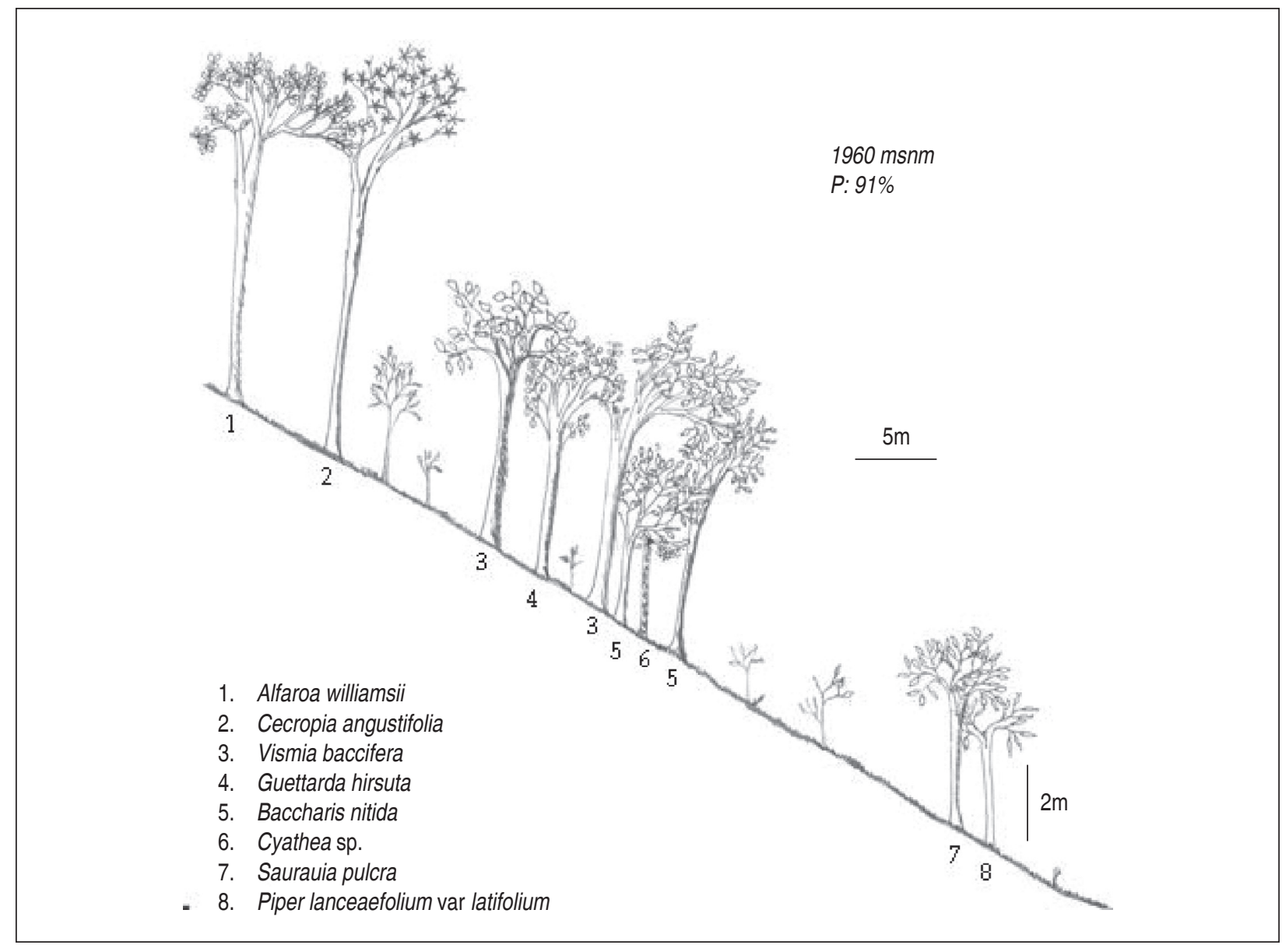

Figura 7. Perfil fisionómico florístico de la comunidad de Baccharis nitida y Sauarauia pulcra. 


\section{Comunidad de Weinmannia pubescens y Clusia dixonii \\ Perfil: Figura 8.}

Anexo 1, Figuras 9 y 10.

Fisionomía: El estrato con mayor cobertura (dominancia) fue el arbóreo inferior cubriendo el 100\% de la parcela. El estrato arbóreo superior obtuvo un $60 \%$ de cobertura (Figura 9). El promedio de alturas de la vegetación de esta comunidad fue el más alto de las demás con 17 m (Figura 10).

Las especies que tienen mayor cantidad de individuos en el estrato arbóreo inferior son $\mathrm{Ani}$ ba coto con siete individuos, $A$. robusta con seis individuos, Miconia resima y Weinmannia pubescens con cinco individuos cada una. La especie más abundante y de mayor cobertura en el estrato arbóreo superior es Clusia dixonii con tres individuos.
Composición: Las especies exclusivas de la comunidad son Clusia dixonii, Aniba coto, Alchornea grandifolia, Weinmannia pubescens, Hyeronima huilensis, Escallonia paniculata, Cinchona officinallis y Freziera carsteniana, por su parte las especies Endlicheria griseo - serícea, Miconia resima, Aniba robusta y Elaeagia myriantha se consideraron las especies electivas de mayor importancia dentro de la comunidad.

Diversidad: Respecto al número de individuos colectados, se deduce que se pueden encontrar en este bosque 132 individuos y 45 especies por 0.1 ha. La riqueza de los estratos demuestra que el estrato herbáceo es el de mayor importancia con 35 especies, mientras que en riqueza de familias, el estrato subarbóreo posee el mayor valor con 19 familias. Las familias más abundantes y más ricas dentro de la asociación son Lauraceae y Rubiaceae con 20 y 15 individuos y con siete y seis especies respectivamente.

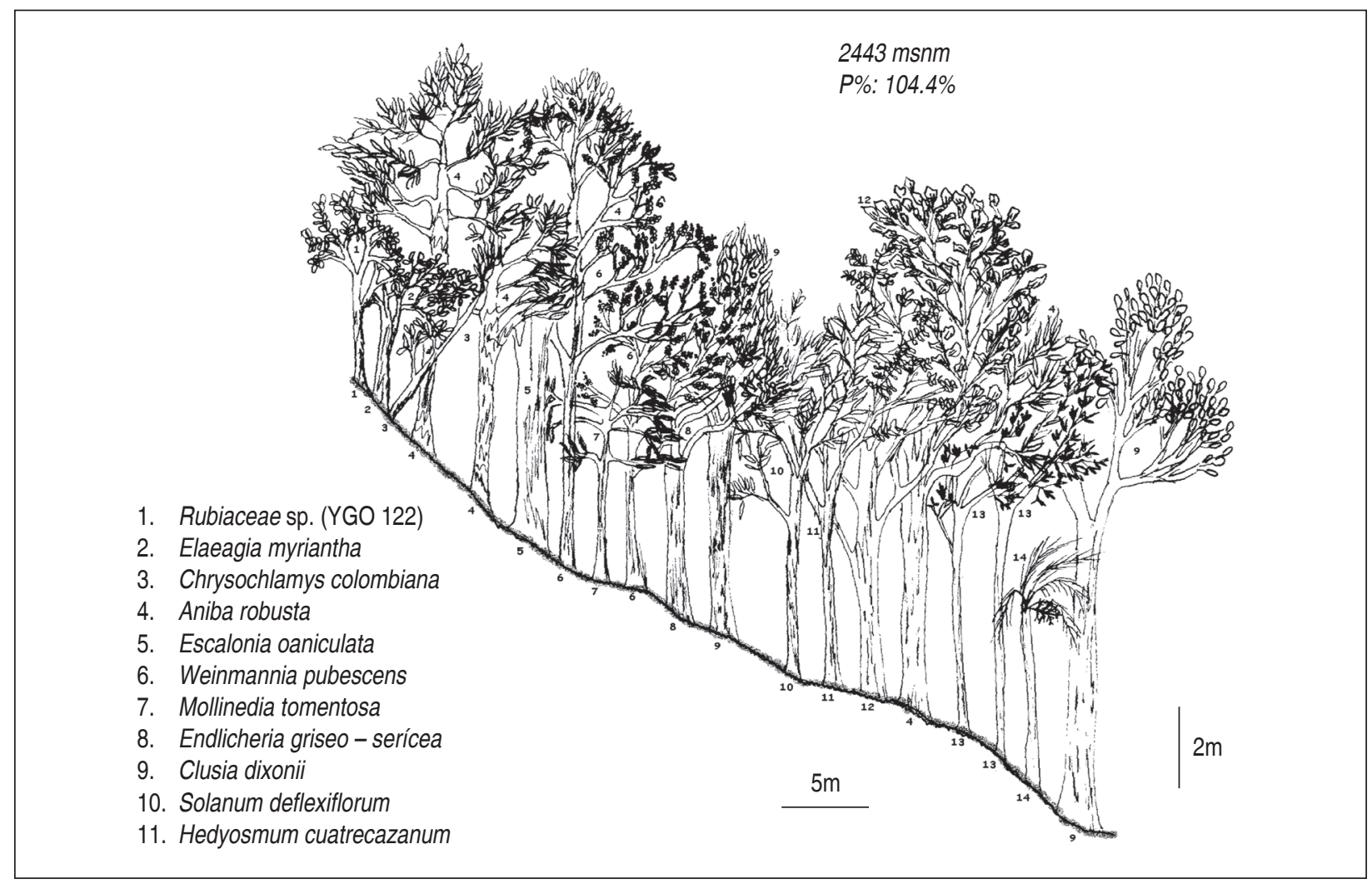

Figura 8. Perfil fisionómico florístico de la comunidad de Weinmannia pubescens y Clusia dixonii. 


\section{ESTRUCTURA}

\section{ALIANZA CYATHEO - CECROPION ANGUSTIFOLIAE}

\section{Estructura horizontal (Anexo 1)}

\section{Distribución de diámetros (Figura 11)}

Se encontraron ocho clases diamétricas, desde la clase I $(10-20 \mathrm{~cm})$ hasta la clase IX $(90 \mathrm{~cm}$ $-100 \mathrm{~cm}$ ). El 58\% de los individuos se concentraron en la clase I $(10.1-20 \mathrm{~cm})$, mientras que en la clase II $(20.1-30 \mathrm{~cm})$ se encontró el 23\% del total. La tendencia se da en J invertida.

\section{Distribución de coberturas (Figura 15)}

Se distribuye en 13 clases, con coberturas desde $1 \mathrm{~m}^{2}$ hasta $130 \mathrm{~m}^{2}$ y rangos con intervalos de $10 \mathrm{~m}^{2}$. Se presenta una distribución en $\mathrm{J}$ invertida. En la clase I $\left(1-10 \mathrm{~m}^{2}\right)$ se presenta la mayor concentración de individuos con el $42 \%$ del total.

\section{Área basal}

Las especies Elaeagia myriantha y Aniba robusta poseen los valores más altos de área basal con 2.05 y $1.65 \mathrm{~m}^{2}$ respectivamente.

\section{Área basal por clases diamétricas} (Figura 12)

Se presenta una uniformidad en los valores de área basal en las primeras cuatro clases, el valor de área basal para la clase II $(20.1-30 \mathrm{~cm})$ es de $4.6 \mathrm{~m}^{2}$, seguido de la clase III $(30.1-40$ $\mathrm{cm})$ con $3.9 \mathrm{~m}^{2}$.

\section{Área basal por clases de altura (Figura 14)} Las clases IV $(14.1-18 \mathrm{~m})$ y VII $(30.1-34 \mathrm{~m})$ presentan los valores más altos de área basal con 5.4 y $4.4 \mathrm{~m}^{2}$ respectivamente.

Índice de Predominio Fisionómico (IPF), de Valor de Importancia (IVI) y de Valor de Importancia Ampliado (IVIA) (Tabla 1)

En los valores de IPF e IVI, las especies Elaeagia myriantha y Aniba robusta ocupan el pri- mer y segundo lugar con 5 y $4 \%$ en IPF y 3\% en IVI para cada una. Las especies $A$. robusta y Cyathea sp. (YGO 045) presentan los mayores valores de Regeneración natural (Rn) y poseen el valor más alto en IVIA con un $4 \%$.

\section{Estructura vertical}

Distribución de alturas (Figura 13)

Se encontraron ocho clases con una tendencia a la normalidad, con variación entre 4 y $32 \mathrm{~m}$. La mayor cantidad de individuos se presenta en las clases II $(6.1-10 \mathrm{~m})$ y IV $(14.1-18 \mathrm{~m})$ con el $26 \%$.

\section{Estratificación según Ogawa (Figura 16)}

Se presentan alturas desde los 4 hasta los $32 \mathrm{~m}$. Se muestra una concentración de puntos que indica la formación de estratos en los individuos con alturas entre los 5 y $12 \mathrm{~m}$, igualmente se presenta una ligera agrupación entre los 12 y 20 $\mathrm{m}$ y los individuos mayores a $20 \mathrm{~m}$ de altura.

\section{Asociación Ladenbergio macrocarpae - Elaeagietum myrianthae}

\section{Estructura horizontal}

\section{Distribución de diámetros (Figura 11)}

La distribución de los individuos se presenta en ocho clases diamétricas. La clase I (10.1 - 20 $\mathrm{cm})$ obtuvo el mayor porcentaje de individuos con el $54 \%$, la clase II $(20.1-30 \mathrm{~cm})$ obtuvo el $23 \%$. El patrón se da en J invertida.

\section{Distribución de coberturas (Figura 15)}

Se presentan seis clases, con una tendencia en $\mathrm{J}$ invertida y coberturas hasta los $96 \mathrm{~m}^{2}$. El $66 \%$ de los individuos se concentra en la clase I $\left(0.1-16 \mathrm{~m}^{2}\right)$, en la clase II $\left(16.1-32 \mathrm{~m}^{2}\right)$ se agrupa el $22 \%$ del total de individuos.

\section{Área basal}

Los valores más altos de área basal por especie fueron para Cecropia angustifolia y una espe- 
cie no identificada Leon sp. (NC) con 1.55 y $1.36 \mathrm{~m}^{2}$ respectivamente.

\section{Área basal por clases diamétricas} (Figura 12)

La distribución es uniforme en las cuatro primeras clases, con una concentración promedio de individuos en las clases II $(20.1-30 \mathrm{~cm})$ a IV $(40.1-50 \mathrm{~cm})$ de $2.5 \mathrm{~m}^{2}$. A diferencia de los demás, el levantamiento 13 presentó una distribución en $\mathrm{J}$ invertida.

\section{Área basal por clases de altura (Figura 14)}

La clase IV $(15.1-20 \mathrm{~m})$ presenta el mayor valor de área basal con $3.5 \mathrm{~m}^{2}$, seguido de la clase VI $(25.1-30 \mathrm{~m})$ con $3.3 \mathrm{~m}^{2}$. En este caso la distribución tiende a la normalidad.

Índice de Predominio Fisionómico (IPF), de Valor de Importancia (IVI) y de Valor de Importancia Ampliado (IVIA) (Tabla 1)

Para este caso Elaeagia myriantha obtuvo los valores más altos en IPF e IVI con 9 y 7\%, seguida de Cecropia angustifolia con 5 y $4 \%$ respectivamente. Aniba robusta y E. myriantha obtuvieron el porcentaje más alto en IVIA con un 5\% cada una. Palicourea cuatrecasasii, posee el valor más alto en $R$.

\section{Estructura vertical}

\section{Distribución de alturas (Figura 13)}

Se encontraron siete clases con variación entre 5 y $35 \mathrm{~m}$. La clase II $(5.1-10 \mathrm{~m})$ presenta la mayor concentración de individuos con un $31 \%$, seguida de la clase III $(10.1-15 \mathrm{~m})$ con el $29 \%$. La distribución de los individuos es normal con una ligera desviación hacia la izquierda.

\section{Estratificación según Ogawa (Figura 16)}

Se presentan dos estratos. Una concentración de individuos marcada entre los 5 y $15 \mathrm{~m}$ de altura, y otra ligeramente definida entre los 15 y $20 \mathrm{~m}$.
Asociación Guettardo hirsutae

- Hedyosmetum translucidi.

\section{Estructura horizontal}

Distribución de diámetros (Figura 11)

La distribución se da en seis clases diamétricas. Se presenta una distribución en J invertida. La mayor cantidad de individuos se concentra en la clase I $(10.1-20 \mathrm{~cm})$ con el $79 \%$ seguida de la clase II $(20.1-30 \mathrm{~cm})$ que agrupa el 14\% del total.

\section{Distribución de coberturas (Figura 15)}

La tendencia se da en $J$ invertida con una distribución en 16 clases, la mayor concentración se presenta en la clase II $\left(16.1-32 \mathrm{~m}^{2}\right)$ con el $52 \%$. La clase I $\left(0.1-16 \mathrm{~m}^{2}\right)$ obtuvo el $32 \%$ del total de individuos.

\section{Área basal}

Los valores más altos de área basal por especie son para Wettinia sp. con $0.37 \mathrm{~m}^{2}$, y para Hedyosmum translucidum y Vochysia megalantha con $0.32 \mathrm{~m}^{2}$ cada una.

\section{Área basal por clases diamétricas}

(Figura 12)

Las clases II $(20.1-30 \mathrm{~cm})$ y I $(10.1-20 \mathrm{~cm})$ tienen los mayores valores, con 0.9 y $0.86 \mathrm{~m}^{2}$ respectivamente.

\section{Área basal por clases de altura (Figura 14)}

Los mayores valores de área basal se presentan en la clase IV $(15.1-20 \mathrm{~m})$ con $1.2 \mathrm{~m} 2$. La clase III (10.1-15m) obtuvo $1 \mathrm{~m}^{2}$.

Índice de Predominio Fisionómico (IPF), de Valor de Importancia (IVI) y de Valor de Importancia Ampliado (IVIA) (Tabla 1)

En los índices de importancia, Wettinia sp. posee los valores más altos, en IPF (15\%), IVI (11\%) e IVIA (15\%). le sigue Hedyosmum translucidum en IPF (10\%) e IVI (7\%). Palicourea cuatrecasasii (con el valor más alto en Rn) y Miconia sp. (CKA 123) también sobresalen en IVIA con 9 y $7 \%$ respectivamente. 


\section{Estructura vertical}

\section{Distribución de alturas (Figura 13)}

Se obtuvieron seis clases con una distribución normal. El 61\% de los individuos se concentra en la clase II ( $5.1-10 \mathrm{~m})$ y el $19 \%$ de los individuos en la clase III $(10.1-15 \mathrm{~m})$.

\section{Estratificación según Ogawa (Figura 16)} Se definieron ligeramente dos estratos, uno entre los 5 y $15 \mathrm{~m}$ y otro con los individuos emergentes de alturas superiores a los $15 \mathrm{~m}$.

Comunidad de Helicostylis tovarensis y Alfaroa williamsii

\section{Estructura horizontal}

Distribución de diámetros (Figura 11)

Se definieron cinco clases diamétricas para la comunidad. El $60 \%$ del total de individuos se concentra en la clase I $(10.1-20 \mathrm{~cm})$, la clase II $(20.1-30 \mathrm{~cm})$ obtuvo el $24 \%$ de los individuos. La distribución se da en J invertida.

\section{Distribución de coberturas (Figura 15)}

Se definieron ocho clases de cobertura, la mayor agrupación de individuos se presenta en la clase I $\left(0.5-14.5 \mathrm{~m}^{2}\right)$ con el $52 \%$ del total. La clase II $\left(14.51-28.5 \mathrm{~m}^{2}\right)$ concentra el $26 \%$.

\section{Área basal}

Alfaroa williamsii y Matudaea colombiana poseen los mayores valores en área basal con 0.92 y $0.62 \mathrm{~m}^{2}$ respectivamente.

\section{Área basal por clases diamétricas}

(Figura 12)

Se encontró una uniformidad en los valores en las cuatro primeras clases con valores entre 1.2 $\mathrm{m}^{2}$ en la clase III $(30.1-40 \mathrm{~cm})$ y $1.6 \mathrm{~m}^{2}$ para la clase II $(20.1-30 \mathrm{~cm})$.

Área basal por clases de altura (Figura 14) Las clases III, IV y V presentan valores de área basal muy similares, con valores de $1.4 \mathrm{~m}^{2}$ en la clase IV $(15.1-20 \mathrm{~m})$ a $1.7 \mathrm{~m}^{2}$ en la clase III $(10.1-15 \mathrm{~m})$.

Índice de Predominio Fisionómico (IPF), de Valor de Importancia (IVI) y de Valor de Importancia Ampliado (IVIA) (Tabla 2)

La especie Alfaroa williamsii, posee los valores más altos en los tres índices con un $13 \%$ en IPF, $8 \%$ en IVI e IVIA. En IPF Hedyosmum cuatrecazanum posee el 6\%. Se destacan Endlicheria cf. griseo - sericea con 5\% en IVI y $4 \%$ en IVIA y Psychotria longirostris con 4\% en IVIA, pese a que no tiene valores altos en los demás índices.

\section{Estructura vertical}

\section{Distribución de alturas (Figura 13)}

Se presentan seis clases de alturas con valores de 2.8 a $30 \mathrm{~m}$. Se presenta una normalidad en los valores con el $36 \%$ de los individuos concentrados en la clase III (10.1 $15 \mathrm{~m})$.

\section{Estratificación según Ogawa (Figura 16)}

No se diferencia un estrato en particular dentro de la asociación, sin embargo algunos puntos se concentran entre los 5 y $15 \mathrm{~m}$ de altura.

Comunidad de Quercus humboldtii y Wettinia fascicularis

\section{Estructura horizontal}

Distribución de diámetros (Figura 11)

Se presenta una distribución en 12 clases diamétricas, con algunos individuos aislados pertenecientes a las dos últimas clases. Se presenta una distribución en $\mathrm{J}$ invertida, la mayoría de los individuos se concentran en la clase I (10.1 $-20 \mathrm{~cm})$ con el $62 \%$, la clase II $(20.1-30 \mathrm{~cm})$ posee el $8 \%$ del total.

\section{Distribución de coberturas (Figura 15)}

Se presentan ocho clases de cobertura. La tendencia se da en J invertida. La concentración 
de individuos se presenta en la clase I $(2.1$ - 11 $\mathrm{m}^{2}$ ) representando el $32 \%$, aunque en el levantamiento No. 15 los individuos se concentran en la clase II $\left(11.1-20 \mathrm{~m}^{2}\right)$, con el $35 \%$.

\section{Área basal}

Las dos especies que dominan en la comunidad son Quercus humboldtii, y Colombobalanus excelsa. Presentan valores de área basal de 7.34 y $4.6 \mathrm{~m}^{2}$ respectivamente frente a $0.34 \mathrm{~m}^{2}$ de Wettinia fascicularis, especie que es característica de la comunidad por su abundancia y representatividad.

\section{Área basal por clases diamétricas \\ (Figura 12)}

Se presenta una tendencia normal con desviación a la derecha, los mayores valores de área basal se presentan en la clase VI (40.1 - 50 $\mathrm{cm})$ y X $(100.1-110 \mathrm{~cm})$ con 2.8 y $2.5 \mathrm{~m}^{2}$ respectivamente.

Área basal por clases de altura (Figura 14) La distribución de los valores de área basal tiende a la normalidad, en la clase III (15.1 $-20 \mathrm{~m}$ ) se presenta un valor de $8.9 \mathrm{~m}^{2}$.

Índice de Predominio Fisionómico (IPF), de Valor de Importancia (IVI) y de Valor de Importancia Ampliado (IVIA) (Tabla 2)

En IPF e IVI dominan Quercus humboldtii con un IPF de $30 \%$ e IVI de $24 \%$, Wettinia fascicularis por su parte posee un $28 \%$ en IPF y $20 \%$ en IVI, Colombobalanus excelsa también es importante con un 18\% y 16\% para cada índice. $W$. fascicularis posee el valor más alto de IVIA con un $36 \%$ y el valor más alto de $\mathrm{Rn}$, seguido de $Q$. humboldtii y $C$. excelsa con un $15 \%$ y $11 \%$ respectivamente.

\section{Estructura vertical}

\section{Distribución de alturas (Figura 13)}

Se observa una distribución en cuatro clases, con alturas entre 5 y $25 \mathrm{~m}$. La mayor cantidad de individuos se concentra en la clase I (5.1 $-10 \mathrm{~m}$ ) con el $55 \%$ del total de individuos. La distribución se asemeja a una J invertida.

\section{Estratificación según Ogawa (Figura 16)}

Se definen tres estratos. Entre los 5 y $12 \mathrm{~m}$ se presenta un estrato, se observa otro estrato hasta los $20 \mathrm{~m}$ y finalmente se observa una concentración de puntos entre 15 y $23 \mathrm{~m}$ de altura.

\section{Comunidad de Baccharis nitida y Saurauia pulchra}

\section{Estructura horizontal}

\section{Distribución de diámetros (Figura 11)}

Se encuentran dos clases diamétricas. Los individuos se concentran en la clase I (10.01-20 $\mathrm{cm})$, con el $62 \%$ del total, la clase II $(20.1-30$ $\mathrm{cm}$ ) agrupa el 38\% restante. La distribución en seis clases que se presenta con amplitudes de $3 \mathrm{~cm}$ entre clases, muestra que el 58\% del total de individuos se concentra en la clase I (10.1 $-13 \mathrm{~cm})$.

\section{Distribución de coberturas (Figura 15)}

Se presentan diez clases de cobertura con una distribución en $\mathrm{J}$ invertida, el 40\% de los individuos se concentran en la clase I $\left(3.1-6 \mathrm{~m}^{2}\right)$. En la clase II $\left(6.1-9 \mathrm{~m}^{2}\right)$ se agrupa el $23 \%$ del total de individuos.

\section{Área basal}

Aunque se presentan valores bajos de área basal, las especies más dominantes son Vismia baccifera con $0.15 \mathrm{~m}^{2}$ y Piper lanceaefolium var latifolium con $0.11 \mathrm{~m}^{2}$.

\section{Área basal por clases diamétricas \\ (Figura 12)}

No se presenta un patrón definido. En la clase I $(10.1-20 \mathrm{~cm})$ el valor más alto se presentó en la clase I con $0.49 \mathrm{~m}^{2}$. En la clase II (20.1 - 30 $\mathrm{cm}$ ) se obtuvo $0.21 \mathrm{~m}^{2}$. 
Área basal por clases de altura (Figura 14)

El valor más alto se presentó en la clase II (5.1 $-10 \mathrm{~m}$ ) con $0.6 \mathrm{~m}^{2}$, seguido de la clase I con $0.07 \mathrm{~m}^{2}$.

Índice de Predominio Fisionómico (IPF), de Valor de Importancia (IVI) y de Valor de Importancia Ampliado (IVIA) (Tabla 2)

Los valores más altos de IPF se presentan para Saurauia pulchra (que posee los valores más altos de Rn) y Piper lanceaefolium var latifolium con el 19 y $18 \%$ del total. En IVI también poseen los valores más altos con $14 \%$ para ambas especies. En IVIA $S$. pulchra obtuvo el $21 \%$ y P. lanceaefolium var latifolium el $13 \%$.

\section{Estructura vertical}

Distribución de alturas (Figura 13)

Se encuentran tres clases con valores que van desde los 4.5 hasta los $13 \mathrm{~m}$. Se presenta una distribución normal. La clase II $(5.1-10 \mathrm{~m})$ representa el $81 \%$, seguida por la clase I con el $14 \%$ del total.

\section{Estratificación según Ogawa (Figura 16)}

Se presenta una ligera concentración de individuos desde los 4,5 hasta los $10 \mathrm{~m}$ de altura, sin embargo no es muy notoria la estratificación debido al estado inicial de sucesión en la que se encuentran estas áreas.

\section{Comunidad de Weinmannia pubescens y Clusia dixonii}

\section{Estructura horizontal}

\section{Distribución de diámetros (Figura 11)}

Se diferencian ocho clases diamétricas, la mayor concentración de individuos se presenta en la clase I $(10.1-20 \mathrm{~cm})$ con el $60 \%$ del total. La clase II $(20.1-30 \mathrm{~cm})$ concentra el $24 \%$ del total de individuos. La distribución se da en J invertida.

\section{Distribución de coberturas (Figura 15)}

Se presenta una distribución normal en ocho clases con una fuerte tendencia hacia la izquierda, con valores hasta los $128 \mathrm{~m}^{2}$. La concentración de individuos se presenta en la clase II $\left(16.1-32 \mathrm{~m}^{2}\right)$ con el $44 \%$, en la clase I $(0.1$ $-16 \mathrm{~m}^{2}$ ) se encuentra el $31 \%$ del total.

\section{Área basal}

En área basal Clusia dixonii y Escallonia paniculata poseen los valores más altos con 0.37 y $0.31 \mathrm{~m}^{2}$ respectivamente.

\section{Área basal por clases diamétricas}

(Figura 12)

Los mayores valores de área basal se presentan en la clase III $(30.1-40 \mathrm{~cm})$ con $1.11 \mathrm{~m}^{2}$ seguido de la clase II $(20.1-30 \mathrm{~cm})$ con $1.05 \mathrm{~m}^{2}$.

\section{Área basal por clases de altura (Figura 14)}

La clase VI $(25.1$ - $30 \mathrm{~m})$ presenta los mayores valores de área basal con $1.3 \mathrm{~m}^{2}$. La distribución de las clases III $(10.1$ - $15 \mathrm{~m})$ a V (20.1 $-25 \mathrm{~m}$ ) presentan uniformidad en sus valores, con un promedio de $0.8 \mathrm{~m}^{2}$.

Índice de Predominio Fisionómico (IPF), de Valor de Importancia (IVI) y de Valor de Importancia Ampliado (IVIA) (Tabla 2)

En los valores de IPF la especie no identificada Rubiaceae sp. (YGO 122) y Aniba coto, obtuvieron los valores más altos con $5 \%$ cada una. En los valores de IVI Clusia dixonii y Rubiaceae sp. (YGO 122) poseen los valores más altos con 5\% respectivamente. En IVIA sobresale Faramea flavicans (7\%), con el valor más alto de Rn, Cyathea sp. (YGO 045) y nuevamente $A$. robusta con el 5\% cada una.

\section{Estructura vertical}

\section{Distribución de alturas (Figura 13)}

Se encontraron seis clases de alturas, con variaciones desde los 5 hasta los $30 \mathrm{~m}$. La tendencia es normal, el $31 \%$ de los individuos se concen- 
tra en la clase III $(10.1-15 \mathrm{~m})$, mientras que el $28 \%$ lo hace en la clase IV $(15.1-20 \mathrm{~m})$.

\section{Estratificación según Ogawa (Figura 16)}

Se encontraron individuos desde los 5 hasta los $32 \mathrm{~m}$ de altura, no se definen estratos, se observa una agrupación de individuos entre los $5 \mathrm{y}$ $20 \mathrm{~m}$ y otra con los individuos mayores a $20 \mathrm{~m}$ que corresponden a los individuos dominantes.

\section{DISCUSIÓN Y CONSIDERACIONES FINALES}

\section{COMPOSICIÓN FLORÍSTICA}

Basados en la tabla florística y de fidelidad (Anexo 2) se observa que la asociación Ladenbergio macrocarpae - Elaeagietum myrianthae, presenta la mayor riqueza de especies y que la comunidad de Weinmannia pubescens y Clusia dixonii, presenta un mayor endemismo local o "exclusividad" que las demás unidades sintaxonómicas, probablemente su ubicación en una zona de transición de la región de vida subandina a la andina $(2443 \mathrm{~m})$ causa que se presenten especies que pertenecen a mayores alturas.

\section{VALORES DE ABUNDANCIA Y RIQUEZA PARA CADA ESTRATO}

En cuanto la diversidad por estratos, en las asociaciones el estrato con mayor número de especies es el arbustivo. En las comunidades la mayor concentración de especies se presentó en el estrato herbáceo a excepción de la comunidad de Quercus humboldtii y Wettinia fascicularis que posee el mayor número de especies en el estrato arbustivo. En la comunidad de Baccharis nitida y Saurauia pulchra debido a su estado sucesional, el estrato rasante fue el de mayor riqueza.

La homogeneidad en los valores de cobertura obtenidos para la comunidad de Quercus hum- boldtii y Wettinia fascicularis es causada por la gran abundancia de individuos en el estrato subarbóreo representados por Wettinia fascicularis que nivelaron los valores de dominancia entre los dos estratos.

La comunidad de Baccharis nitida y Saurauia pulchra se encuentra compuesta por levantamientos realizados en áreas intervenidas, con presencia de elementos arbóreos. La dominancia del estrato subarbóreo en esta comunidad se debe a la presencia de individuos remanentes de bosque y al desarrollo de algunas especies heliófitas de mayor porte dentro de la comunidad.

En las asociaciones no se presentaron variaciones notables en los valores de distribución de diámetros; de esta manera en áreas de mayor intervención se definieron menos cantidad de clases diamétricas. Para las comunidades, las diferencias en la distribución de clases se atribuyen a las diferencias florísticas entre ellas.

La distribución de coberturas nos indica que en la asociación Guettardo hirsutae - Hedyosmetum translucidi se encuentran menores coberturas por individuo respecto a la asociación Ladenbergio macrocarpae - Elaeagietum myrianthae, dado por la concentración de individuos en la primera clase.

En la Comunidad de Helicostylis tovarensis y Alfaroa williamsii, se presenta mayor concentración de individuos en la primera clase respecto a las demás comunidades. Al comparar las comunidades definidas para áreas boscosas se observa que la homogeneidad en la distribución de copas hace que se presente mayor diversidad y la presencia de individuos con altas coberturas hace que se origine una mayor dominancia y por lo tanto disminuya la diversidad.

Los índices de valor de importancia tienen una relación indirecta con la diversidad. En la co- 
munidad de Weinmannia pubescens y Clusia dixonii se presenta uniformidad en los valores de IPF e IVI por lo cual la importancia ecológica y fisionómica de las especies está igualmente repartida. En la comunidad de Quercus humboldtii y Wettinia fascicularis sucede lo contrario, los valores de importancia recaen sobre unas pocas especies, disminuyendo la diversidad.

Aunque los bosques muestreados en el corredor biológico se encuentran en la región de vida subandina, dentro de ellos se presenta un alto endemismo reflejado en las diferencias florísticas de cada bosque y con excepción de los robledales, en la equitatividad en los índices de importancia ecológica y fisonómica de las especies; por lo que su adecuado manejo será fundamental para el mantenimiento de los bienes y servicios que se desprenden de su conservación.

El conocimiento de la composición florística y de la estructura de las áreas intervenidas sirve de apoyo para realizar proyectos de manejo y restauración de estas zonas. La reducción continua de la cobertura boscosa origina un incremento importante de las áreas de "rastrojo", convirtiéndose en un componente principal en los proyectos forestales. Esta tendencia hace que a futuro el estudio de la conformación y dinámica de las áreas intervenidas sea cada vez más relevante.

\section{AGRADECIMIENTOS}

Agradecemos a la Corporación Autónoma del Alto Magdalena CAM por el financiamiento del presente trabajo; a la Ingeniera Gloria Ramírez quien fue nuestro apoyo logístico durante la fase de ejecución; al grupo técnico del corredor biológico y los auxiliares de campo por su ayuda oportuna durante la fase de campo; al Herbario Nacional Colombiano (COL) como al Herbario Forestal de la Universidad Distrital "Francisco José de Caldas" (UDBC) y a sus directores Julio Betancourt y Rocío Cortés-B por brindarnos el espacio necesario para la identificación; a los especialistas y al Ingeniero Germán Tellez por la asesoría en la identificación de las especies. Al Doctor Orlando Rangel Ch., por sus valiosos aportes en la edición de este documento. Al Ingeniero Harold Garay por el análisis Twinspan en la parte ecológica y al laboratorio de suelos de la Universidad Distrital por la caracterización de las muestras de suelos.

\section{REFERENCIAS BIBLIOGRÁFICAS}

Bello, A. \& Kattib. 1994. Aspectos ecológicos en la sucesión secundaria de la vegetación subandina $(2010-2510 \mathrm{~m})$ en localidades del municipio de Santa Rosa de Cabal. Risaralda, Colombia. Trabajo de grado. Departamento de Biología. Universidad Nacional. Bogotá.

Bernal, A. 1973. Estudio de la vegetación y planificación preliminar del Parque Nacional Natural Cueva de los Guácharos, Acevedo, Huila. Bogotá D.C., Colombia. Trabajo de grado (Ingeniero Forestal). Universidad Distrital Francisco José de Caldas.

CCAD-PNUD/GEF. 2002. Corredor biológico mesoamericano, una plataforma para el desarrollo sostenible regional. Serie técnica No. 1. Proyecto para la consolidación del corredor biológico mesoamericano. Managua, Nicaragua. 24 p.

Cantillo, E., K. Rodríguez \& A. Avella. 2005. Caracterización florística, estructural, diversidad y ordenación de la vegetación arbórea en la reserva forestal Cárpatos (Guasca - Cundinamarca) Universidad Distrital "Francisco José de Caldas" Ingeniería Forestal.

Cleef, A. 1972. Informe preliminar sobre la botánica del Parque Nacional Natural Cueva de los Guácharos. Bogotá. Colombia. 
Coca, C. \& Y. González. 2007. Caracterización florística y estructural de la vegetación del corredor biológico entre los Parques Nacionales Naturales Puracé - Cueva de los Guácharos. Trabajo de grado (Ingeniero Forestal). Universidad Distrital Francisco José de Caldas. Bogotá D.C., Colombia. $282 \mathrm{p}$.

González Y., C. Coca \& G. Téllez. 2008. Catálogo de la flora vascular de los bosques andinos y subandinos del corredor biológico entre los Parques Nacionales Naturales Puracé - Cueva de los Guácharos. Universidad Distrital Francisco José de Caldas.

Cuatrecasas, J. 1958. Aspectos de la vegetación natural de Colombia. Rev. Acad. Colomb. Cienc. 10(40): 221-268.

Duque-N., A. 1987. Comunidades vegetales de la zona paramuna del PNN Puracé (Colombia). Tesis de grado, Universidad del Valle. (Mimeografiado).

Duque-N., A. \& J.O Rangel-Ch. 1989. Análisis fitosociológico de la vegetación paramuna del PNN Puracé. En: L. F. Herrera, R. Drenan y C. Uribe (eds). Cazicazgos prehispánicos del Valle de la Plata. Tomo I. El contexto medioambiental de la ocupación humana. U. of Pittsburg memoirs in Latin América-Archaeology. 2:70-95.

Holdridge, L. R. 1979. Ecología basada en zonas de vida. Costa Rica. Publicaciones del IICA.

Lozano, G., J. Hernández \& J. Henao 1979. El género Trigonobalanus en el Neotrópico. I. Caldasia 12: 517 - 537.

Mahecha, G. E. 1999. Estudio florístico de la región del macizo colombiano. Principios y procedimientos para el conocimiento de las plantas superiores del trópico americano. Convenio Intercorporativo del Macizo Colombiano. Huila, Colombia.

Rangel-Ch., J. O. \& P. Franco R. 1985. Observaciones fitoecológicas en varias regiones de vida de la cordillera central de Colombia. Caldasia 14 (67): 210-249.

Rangel-Ch., J. O. \& G. Lozano 1986. Un perfil de vegetación entre la Plata Huila y el volcán del Puracé. Caldasia 14 (68-70) $503-547$.

Rangel-Ch., J. O., A. M. Cleef, T. Van Der Hammen \& R. Jaramillo 1982. Tipos de vegetación en el transecto Buritaca - $\mathrm{La}$ Cumbre Sierra Nevada de Santa Marta (entre 0 y $4100 \mathrm{msnm})$. Colombia geográfica 10(1): 1-18.

Rangel-Ch., J. O., A. M. Cleef \& S. Salamanca 2003. The ecuatorial interandean and subandean forest of the Parque los $\mathrm{Ne}$ vados Transect, Cordillera Central, Colombia. 143-204 p. En: T. van der Hammen \& A. Dos Santos (eds). La Cordillera Central Colombiana. Estudio de Ecosistemas Tropandinos 5. J. Cramer, Berlín-Stuttgart.

Rojas, O. 1984. Evolución de una sucesión vegetal en el Valle del Cauca. Cespedesia $13(49-50)$ 152-211.

Sánchez, J. 2003. Aves del corredor biológico entre los Parques Nacionales Naturales Puracé - Cueva de los Guácharos. Guía de Campo. 358 p. 
ANEXO 1

Diagrama estructural: cobertura por estratos

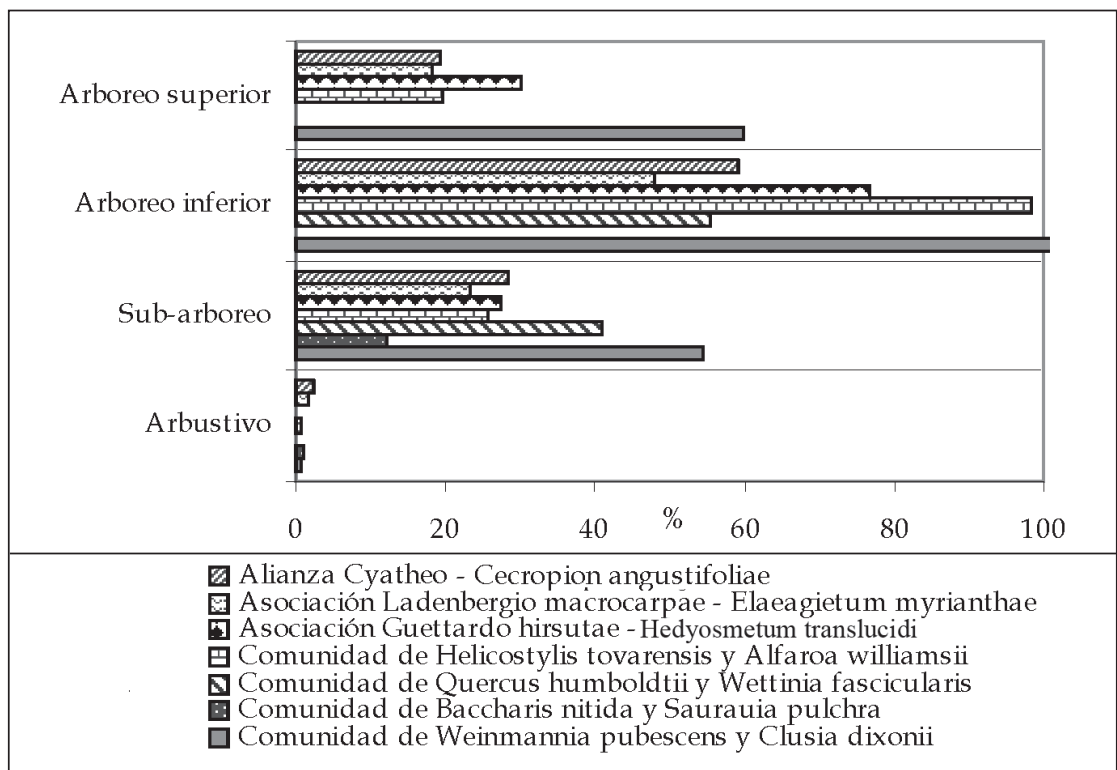

\begin{tabular}{|l|c|c|c|c|}
\hline \multicolumn{1}{|c|}{ Estratos } & Arbustivo & $\begin{array}{c}\text { Sub- } \\
\text { arboreo }\end{array}$ & $\begin{array}{c}\text { Arboreo } \\
\text { inferior }\end{array}$ & $\begin{array}{c}\text { Arboreo } \\
\text { superior }\end{array}$ \\
\cline { 2 - 5 } & $\mathbf{5 - 1 , 5}$ & $\mathbf{1 2 - 5}$ & $\mathbf{2 5 - 1 2}$ & $\mathbf{2 5 m}$ \\
\hline Alianza Cyatheo - Cecropion angustifoliae & 2,35 & 28,46 & 59,21 & 19,36 \\
\hline Asociación Ladenbergio macrocarpae - Elaeagietum myrianthae & 1,70 & 23,35 & 47,96 & 18,19 \\
\hline Asociación Guettardo hirsutae - Hedyosmetum translucidi & 0,40 & 27,25 & 76,81 & 29,90 \\
\hline Comunidad de Helicostylis tovarensis y Alfaroa williamsii & 0,70 & 25,56 & 98,47 & 19,55 \\
\hline Comunidad de Quercus humboldtii y Wettinia fascicularis & - & 40,95 & 55,33 & - \\
\hline Comunidad de Baccharis nitida y Saurauia pulchra & 1,10 & 12,00 & - & - \\
\hline Comunidad de Weinmannia pubescens y Clusia dixonii & 0,80 & 54,50 & 153,61 & 59,80 \\
\hline
\end{tabular}

Figura 9. Cobertura por estratos para las unidades taxonómicas.

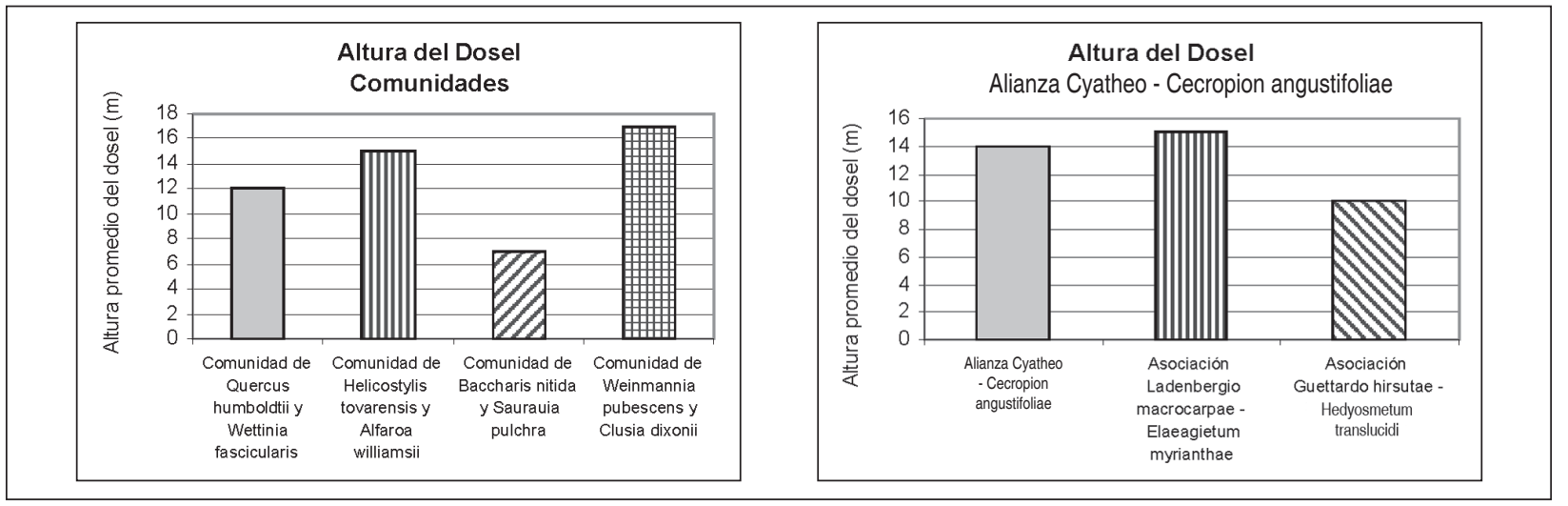

Figura 10. Altura del dosel para las asociaciones y comunidades. 


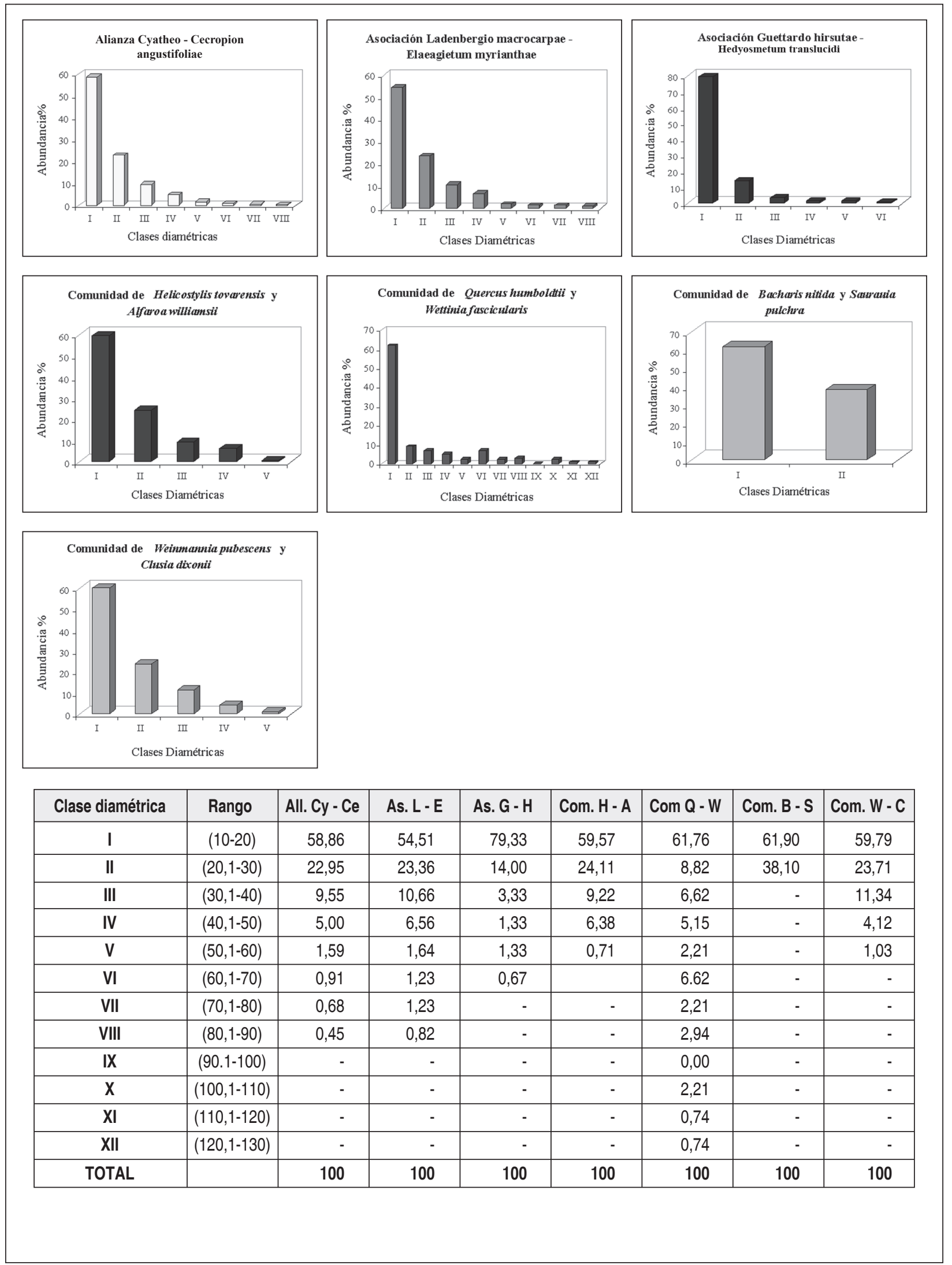

Figura 11. Distribución de diámetros por unidad sintaxonómica para individuos con DAP $\geq 10 \mathrm{~cm}$. 


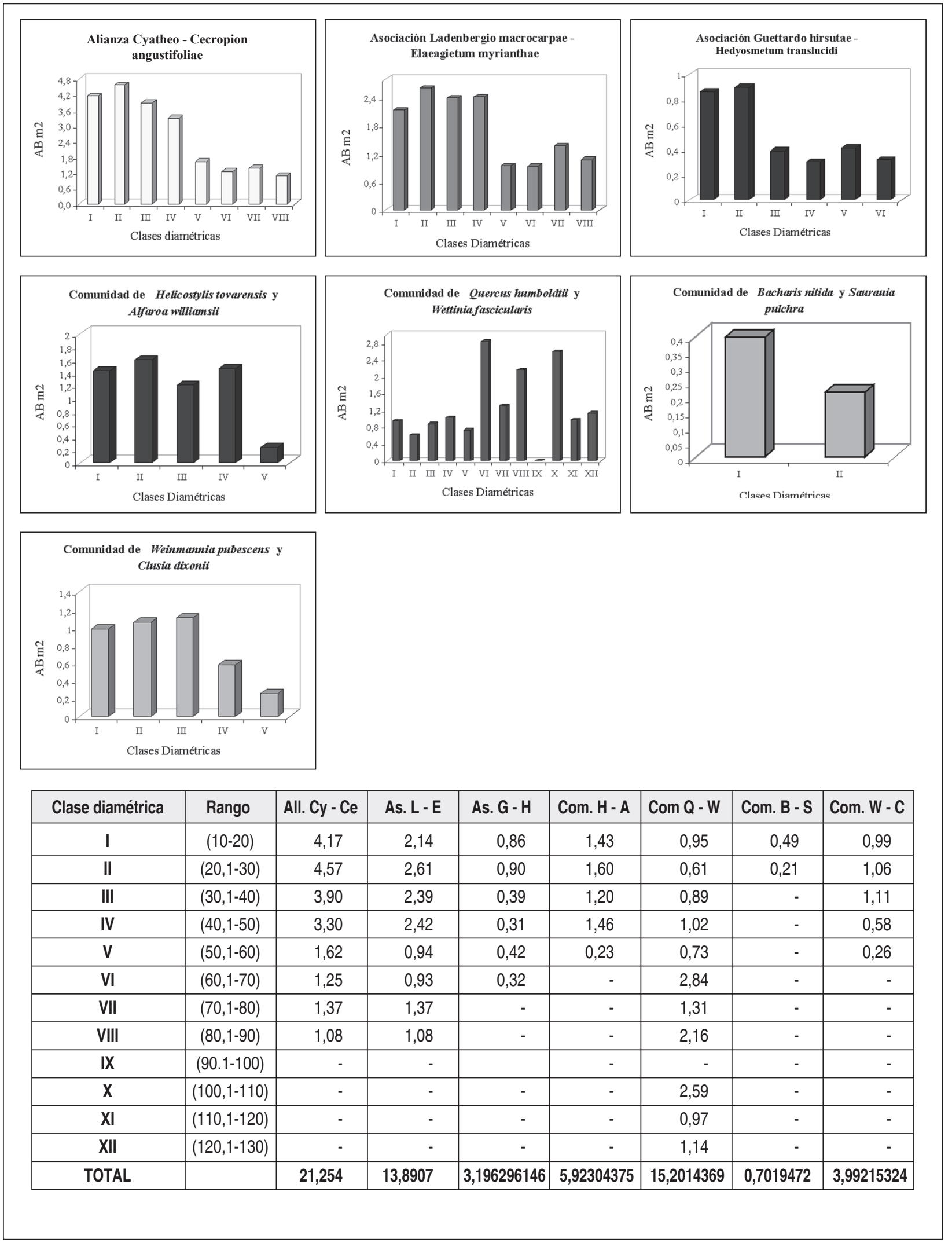

Figura 12. Distribución del área basal por clase diamétrica para individuos con DAP $\geq 10 \mathrm{~cm}$, para las unidades sintaxonómicas. 


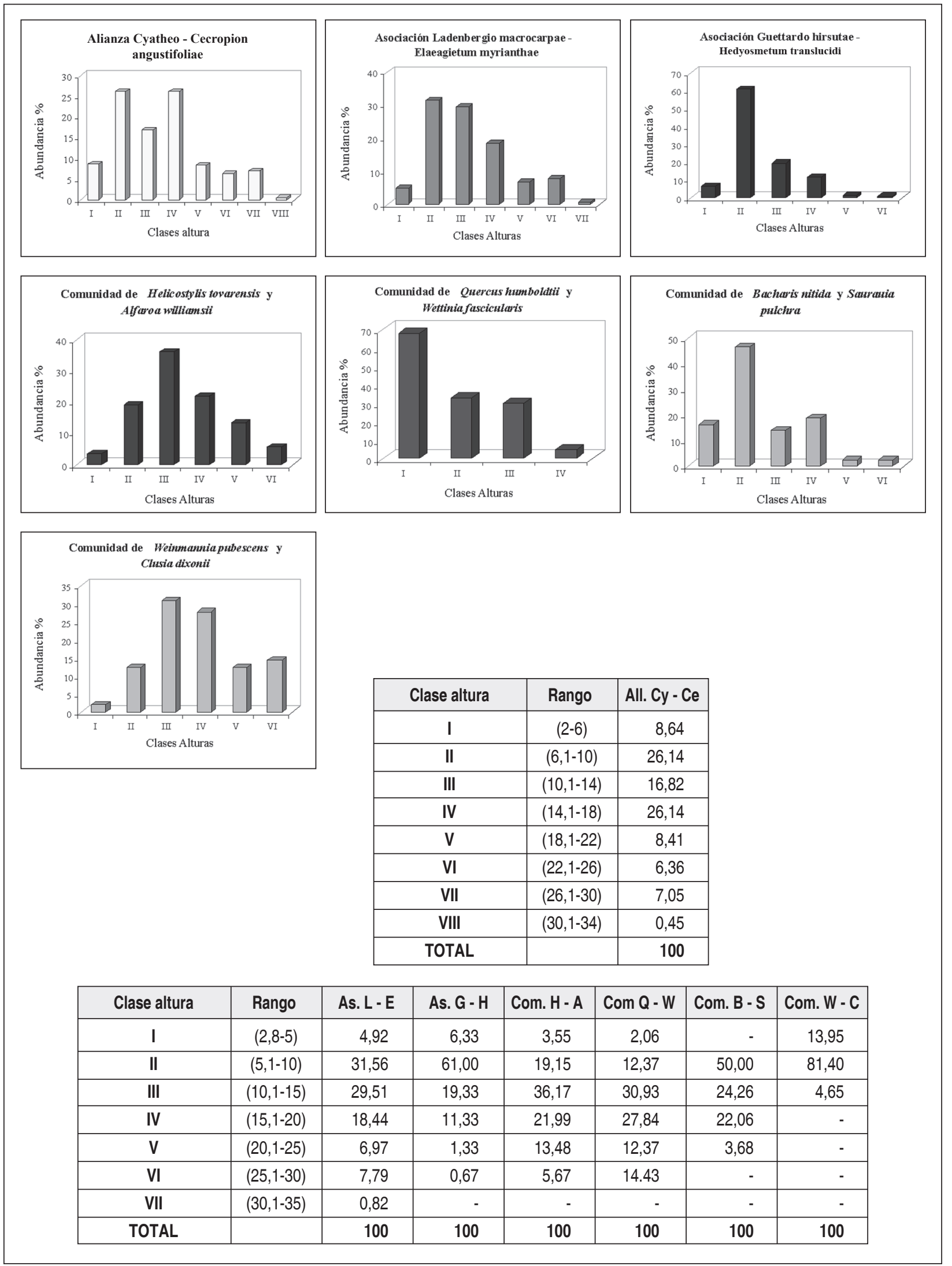

Figura 13. Distribución de alturas por unidad sintaxonómica para los individuos con DAP $\geq 10 \mathrm{~cm}$. 


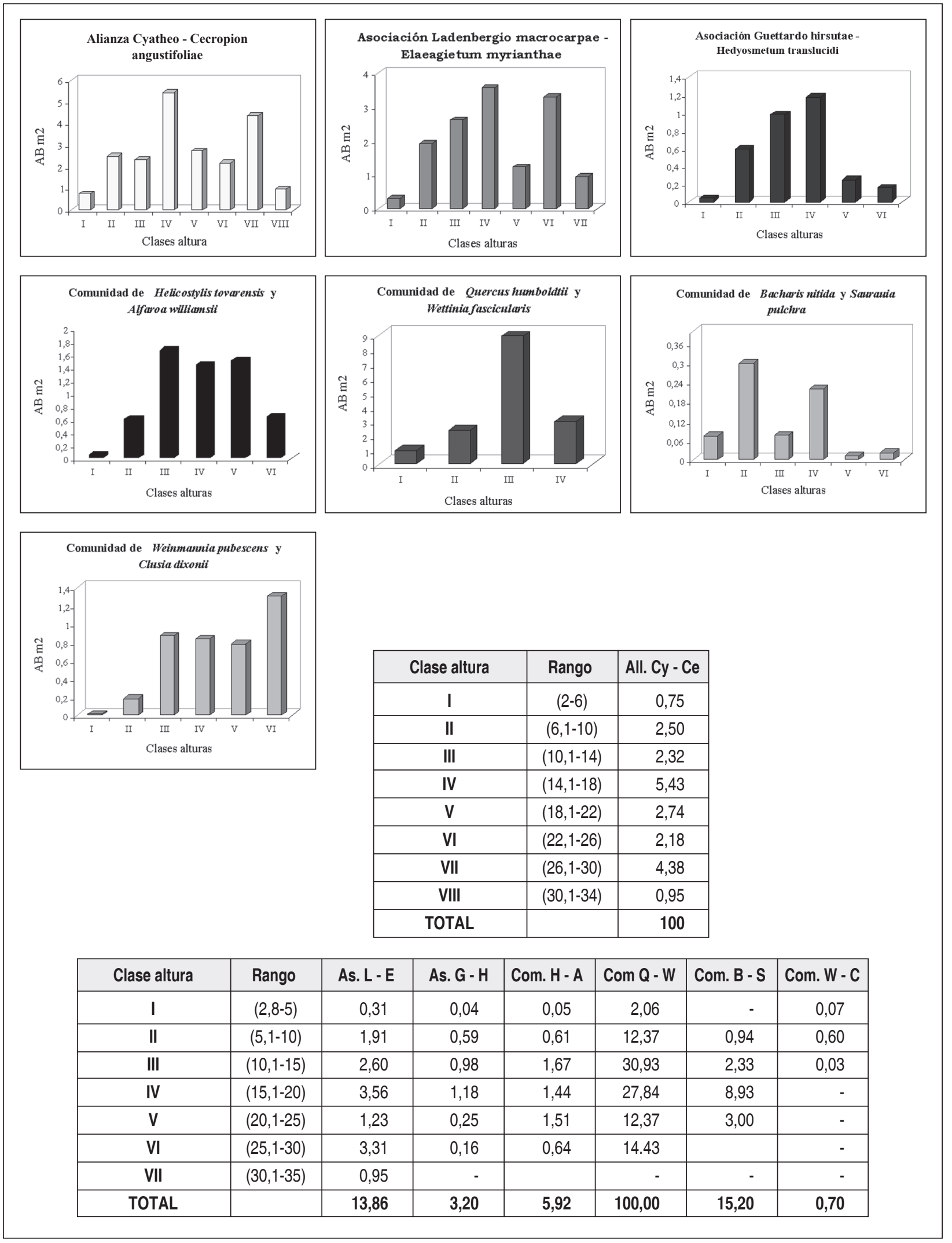

Figura 14. Distribución del área basal por clases diamétricas para los individuos con $D A P \geq 10 \mathrm{~cm}$, para las unidades sintaxonómicas. 


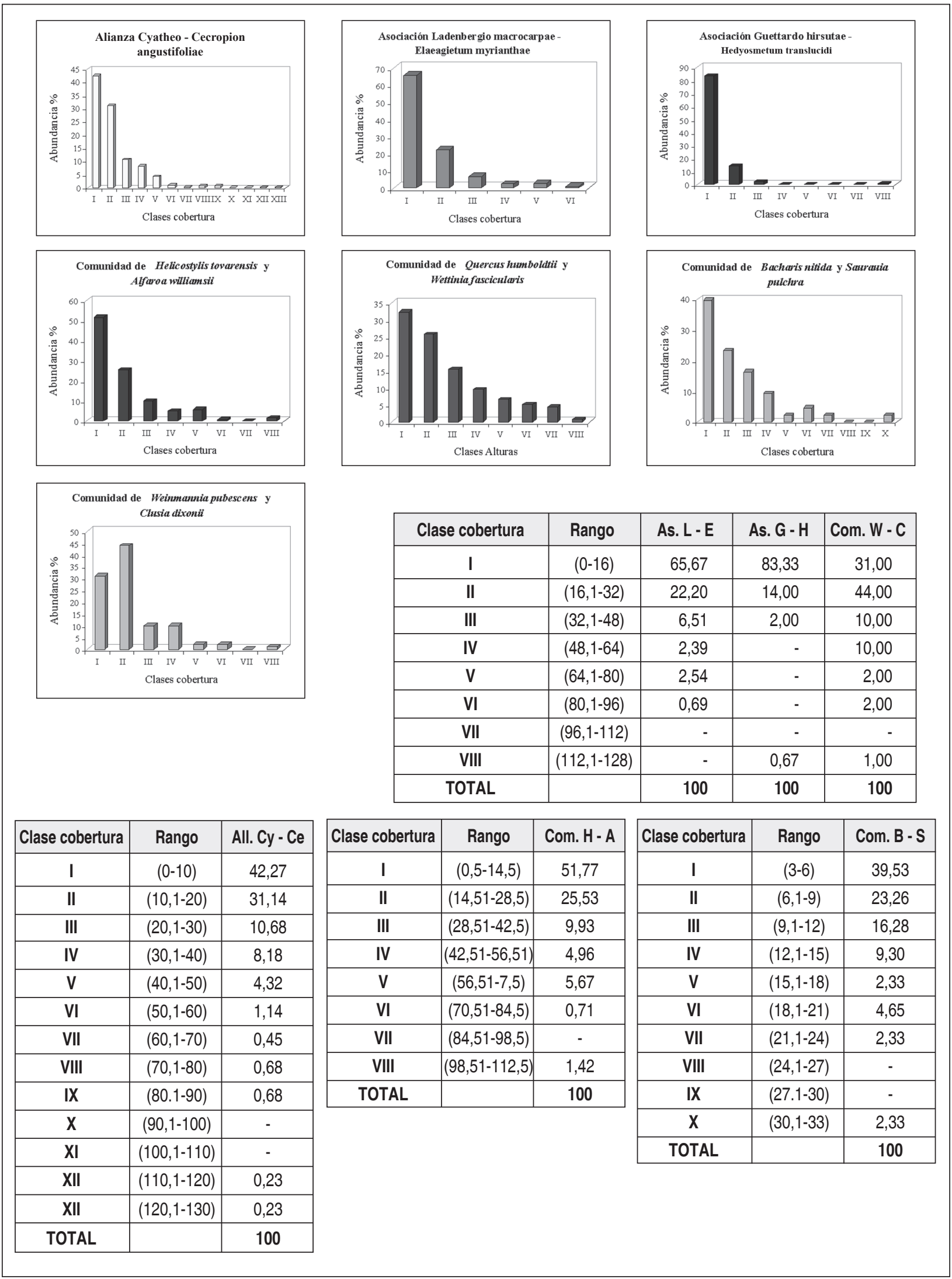

Figura 15. Distribución de cobertura por unidad sintaxonómica para individuos con DAP $\geq 10 \mathrm{~cm}$. 

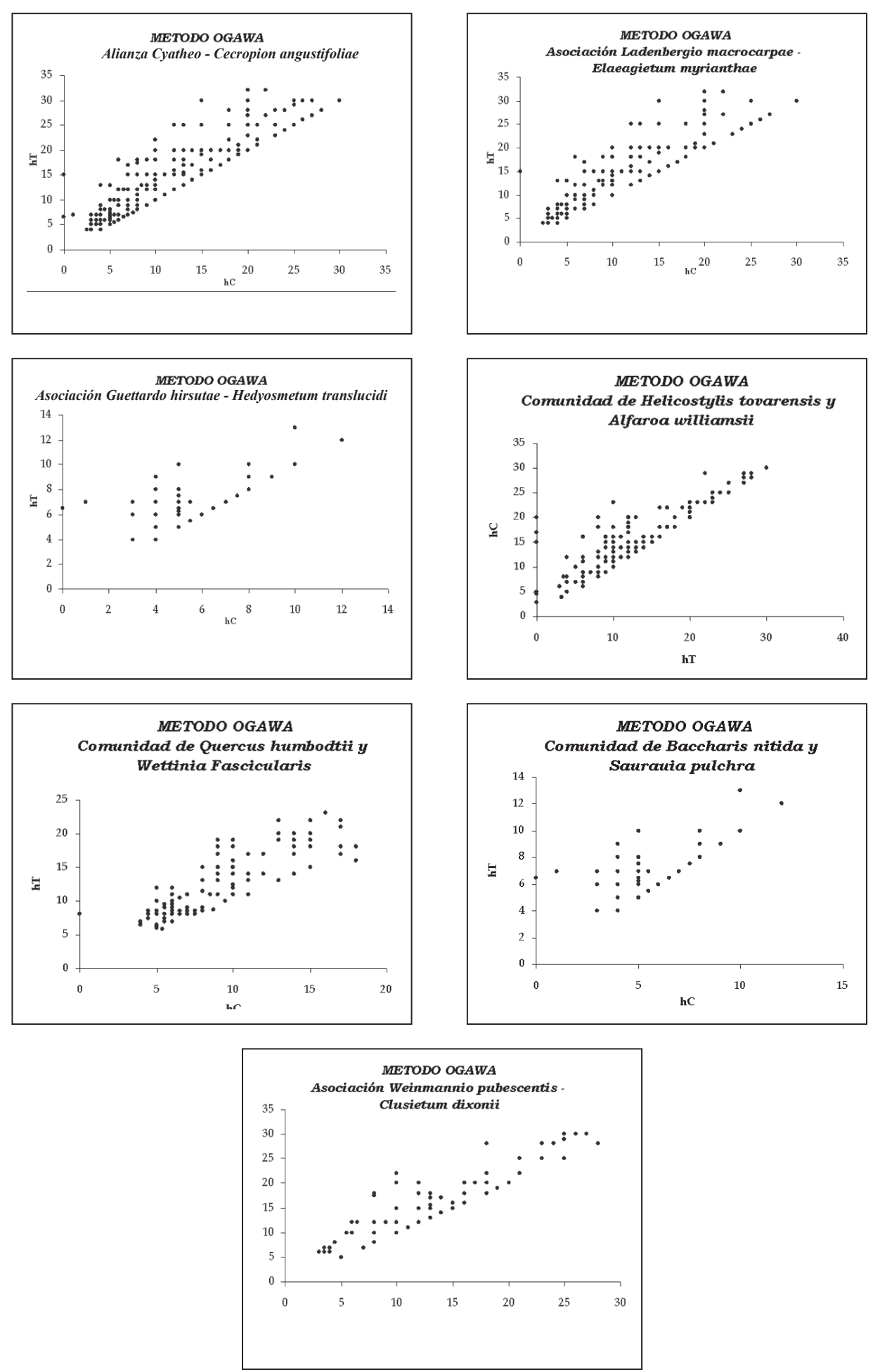

Figura 16. Estratificación según Ogawa para las unidades sintaxonómicas. 
Tabla 1. IPF, IVI e IVIA para las asociaciones.

\begin{tabular}{|c|c|c|c|c|c|c|c|c|}
\hline \multirow{10}{*}{ 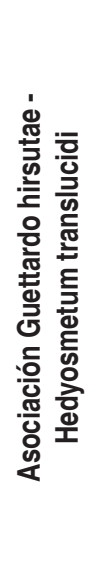 } & Especie & Familia & IPF & IPF\% & IVI & IVl\% & IVIA & IVIA\% \\
\hline & Elaeagia myriantha & Rubiaceae & 27,5 & 9,2 & 20,7 & 6,9 & 15,7 & 5,2 \\
\hline & Cecropia angustifolia & Cecropiaceae & 16,5 & 5,5 & 13,4 & 4,5 & 14,1 & 4,7 \\
\hline & Aniba robusta & Lauraceae & 14,6 & 4,9 & 13,0 & 4,3 & 16,1 & 5,4 \\
\hline & Leon sp. (N.C) & Indeterminada & 16,7 & 5,6 & 12,1 & 4,0 & 5,5 & 1,8 \\
\hline & Hedyosmum cuatrecazanum & Chloranthaceae & 12,2 & 4,1 & 11,8 & 3,9 & 13,2 & 4,4 \\
\hline & Cyathea sp. 1 (YGO 45) & Cyatheaceae & 7,3 & 2,4 & 10,1 & 3,4 & 15,3 & 5,1 \\
\hline & Saurauia pulchra & Actinidaceae & 10,7 & 3,6 & 9,5 & 3,2 & 15,4 & 5,1 \\
\hline & Helicostylis tovarensis & Moraceae & 10,3 & 3,4 & 9,4 & 3,1 & 13,1 & 4,4 \\
\hline & \multicolumn{2}{|l|}{ OTRAS ESPECIES (9 a 73) } & 178,3 & 59,4 & 191,5 & 63,9 & 184,6 & 61,5 \\
\hline \multirow{11}{*}{ 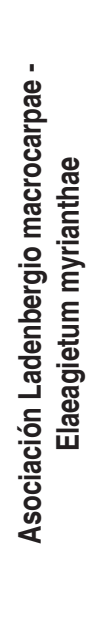 } & Wettinia sp & Arecaceae & 45,6 & 15,2 & 34,8 & 11,6 & 45,3 & 15,1 \\
\hline & Hedyosmum translucidum & Cloranthaceae & 29,2 & 9,7 & 21,6 & 7,2 & 18,1 & 6,0 \\
\hline & Miconia sp. 2 (CKA 123) & Melastomataceae & 25,2 & 8,4 & 18,4 & 6,1 & 21,1 & 7,0 \\
\hline & Vochysia megalantha & Vochisiaceae & 13,4 & 4,5 & 14,5 & 4,8 & 7,0 & 2,3 \\
\hline & Viburnum cornifolium & Caprifoliaceae & 16,4 & 5,5 & 14,1 & 4,7 & 12,7 & 4,2 \\
\hline & Guettarda hirsuta & Rubiaceae & 11,2 & 3,7 & 13,6 & 4,5 & 13,3 & 4,4 \\
\hline & Lozania mutisiana & Lacistemataceae & 15,0 & 5,0 & 13,5 & 4,5 & 14,0 & 4,7 \\
\hline & Ladenbergia macrocarpa & Rubiaceae & 13,4 & 4,5 & 13,1 & 4,4 & 7,6 & 2,5 \\
\hline & Palicourea cuatrecasasii & Rubiaceae & 2,7 & 0,9 & 4,9 & 1,6 & 26,9 & 9,0 \\
\hline & Mollilnedia repanda & Monimiaceae & 12,6 & 4,2 & 12,5 & 4,2 & 11,1 & 3,7 \\
\hline & \multicolumn{2}{|l|}{ OTRAS ESPECIES (12 a 28) } & 115,3 & 38,4 & 139,1 & 46,4 & 123,0 & 41,0 \\
\hline
\end{tabular}


Tabla 2. IPF, IVI e IVIA para las comunidades.

\begin{tabular}{|c|c|c|c|c|c|c|c|c|}
\hline \multirow{7}{*}{ 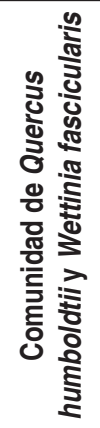 } & Especie & Familia & IPF & IPF\% & IVI & IVl\% & IVIA & IVIA \% \\
\hline & Wettinia fascicularis & Arecaceae & 83,8 & 27,9 & 60,4 & 20,2 & 106,8 & 35,6 \\
\hline & Quercus humboldtii & Fagaceae & 90,2 & 30,1 & 71,5 & 23,8 & 44,7 & 14,9 \\
\hline & Colombobalanus excelsa & Fagaceae & 53,5 & 17,8 & 49,0 & 16,4 & 34,4 & 11,5 \\
\hline & Alfaroa williamsii & Juglandaceae & 6,8 & 2,3 & 7,8 & 2,6 & 16,1 & 5,4 \\
\hline & Dictyocaryum lamarckianum & Arecaceae & 8,0 & 2,7 & 13,0 & 4,3 & 10,9 & 3,6 \\
\hline & \multicolumn{2}{|l|}{ OTRAS ESPECIES (4 a 26) } & 31,0 & 22,8 & 57,8 & 19,3 & 13,5 & 33,0 \\
\hline \multirow{7}{*}{ 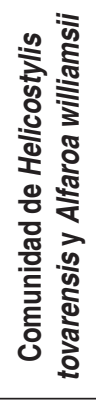 } & Alfaroa cf. williamsii & Juglandaceae & 38,4 & 12,8 & 25,1 & 8,4 & 25,1 & 8,4 \\
\hline & Endlicheria cf griseo-sericea & Lauraceae & 15,6 & 5,2 & 15,1 & 5,0 & 14,6 & 4,9 \\
\hline & Matudaea colombiana & Euphorbiaceae & 15,1 & 5,0 & 14,8 & 4,9 & 11,7 & 3,9 \\
\hline & Hedyosmum cuatrecazanum & Cloranthaceae & 18,5 & 6,2 & 13,8 & 4,6 & 13,0 & 4,3 \\
\hline & Helicostylis tovarensis & Moraceae & 14,0 & 4,7 & 12,5 & 4,2 & 12,5 & 4,2 \\
\hline & Cecropia angustifolia & Cecropiaceae & 14,6 & 4,9 & 10,2 & 3,4 & 10,6 & 3,5 \\
\hline & \multicolumn{2}{|l|}{ OTRAS ESPECIES (7 a 54) } & 183,9 & 61,3 & 208,6 & 69,5 & 212,6 & 70,9 \\
\hline \multirow{7}{*}{ 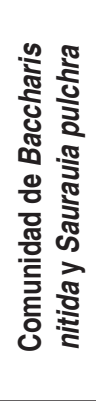 } & Saurauia pulchra & Actinidiaceae & 57,2 & 19,1 & 46,8 & 15,6 & 62,8 & 20,9 \\
\hline & Baccharis nitida & Asteraceae & 30,2 & 10,1 & 34,9 & 11,7 & 38,1 & 12,7 \\
\hline & Piper cf. aduncum & Piperaceae & 43,6 & 14,5 & 30,9 & 10,3 & 31,4 & 10,5 \\
\hline & Vismia lauriformis & Hypericaceae & 35,5 & 11,8 & 30,2 & 10,1 & 20,8 & 6,9 \\
\hline & Cyathea sp. & Cyatheaceae & 24,1 & 8,0 & 26,8 & 8,9 & 25,9 & 8,6 \\
\hline & Alfaroa cf. williamsii & Juglandaceae & 17,4 & 5,8 & 18,6 & 6,2 & 13,6 & 4,5 \\
\hline & \multicolumn{2}{|l|}{ OTRAS ESPECIES (7 a 18) } & 92,0 & 30,7 & 111,8 & 37,3 & 107,5 & 35,8 \\
\hline \multirow{10}{*}{ 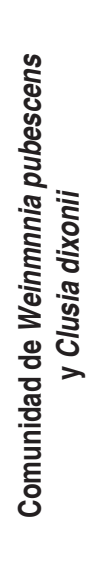 } & Clusia dixonii & Clusiaceae & 13,6 & 4,6 & 16,1 & 5,4 & 11,4 & 3,8 \\
\hline & Rubiaceae sp. (YGO 122) & Rubiaceae & 16,4 & 5,5 & 15,8 & 5,3 & 14,3 & 4,8 \\
\hline & Alchornea grandiflora & Euphorbiaceae & 13,7 & 4,6 & 15,6 & 5,2 & 13,8 & 4,6 \\
\hline & Aniba robusta & Lauraceae & 14,8 & 4,9 & 15,6 & 5,2 & 15,4 & 5,1 \\
\hline & Weinmannia pubescens & Cunnoniaceae & 13,2 & 4,4 & 15,1 & 5,0 & 14,1 & 4,7 \\
\hline & Aniba coto & Lauraceae & 16,0 & 5,4 & 13,9 & 4,6 & 15,6 & 5,2 \\
\hline & Cyathea sp. 1 (YGO 45) & Cyatheaceae & 13,3 & 4,4 & 11,2 & 3,7 & 15,8 & 5,3 \\
\hline & Faramea flavicans & Rubiaceae & 7,2 & 2,4 & 7,1 & 2,4 & 22,5 & 7,5 \\
\hline & Miconia resima & Melastornataceae & 12,6 & 4,2 & 13,8 & 4,6 & 13,3 & 4,4 \\
\hline & \multicolumn{2}{|l|}{ OTRAS ESPECIES (10 a 42) } & 179,2 & 59,7 & 176,1 & 58,7 & 164,0 & 54,7 \\
\hline
\end{tabular}




\section{ANEXO 2}

\section{Tabla florística y de fidelidad}

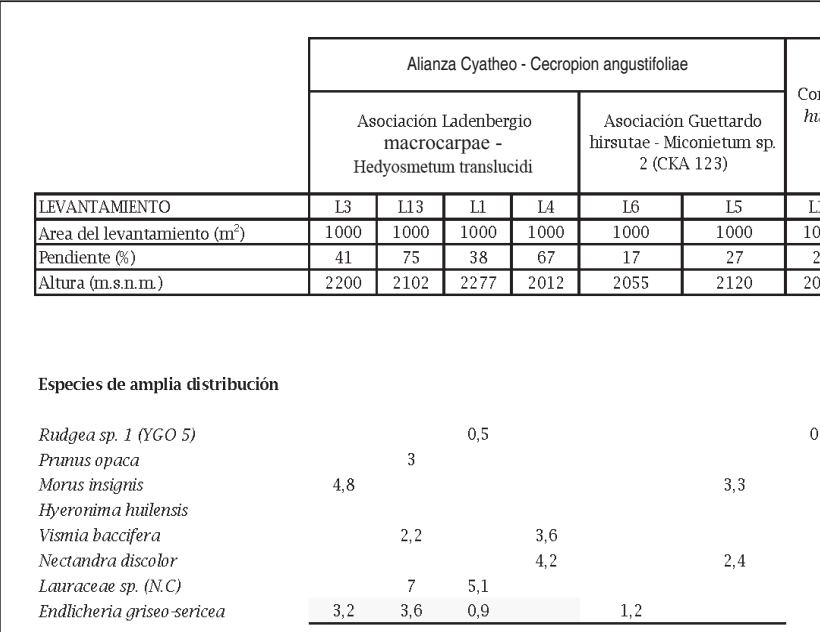

Especies características de la alianza Cyatheo - Cecropion angustifoliae

\begin{tabular}{l|ccccc|} 
Cyathea asp. 1 (YGO 45) & 1,0 & 2,5 & 1,4 & 0,8 & 0,4 \\
Cecropia angustifolia & 4,0 & 8,4 & & 9,9 & 0,6 \\
Heliocarpus americanus & 10,8 & 1,9 & & & 3,4 \\
Hedyosmum cuatrecazanum & 8,9 & 1,8 & & 1,5 & \\
\hline
\end{tabular}

\begin{tabular}{|c|c|c|c|c|c|c|c|c|c|}
\hline \multicolumn{3}{|c|}{$\begin{array}{l}\text { Comunidad de Quercus } \\
\text { humboldtii y Wettinia } \\
\text { fascicularis }\end{array}$} & \multicolumn{2}{|c|}{$\begin{array}{l}\text { Comunidad de } \\
\text { Helicostylis tovarensis } \\
\text { y Alfaroa williamsü }\end{array}$} & \multicolumn{4}{|c|}{$\begin{array}{c}\text { Commidad de Baccharis nitida y } \\
\text { Saurana pulchra }\end{array}$} & \multirow{2}{*}{\begin{tabular}{|c}
$\begin{array}{c}\text { Comunidad de } \\
\text { Weinmanmia } \\
\text { pubescens y Clusia } \\
\text { dixonii }\end{array}$ \\
I2
\end{tabular}} \\
\hline 4 & L15 & L16 & L7 & L10 & L11 & $\mathrm{L} 12$ & L8 & L9 & \\
\hline 000 & 1000 & 1000 & 1000 & 1000 & 500 & 500 & 750 & 1000 & 1000 \\
\hline 23 & 47 & 39 & 45 & 40 & 4,5 & 58 & 34 & 68 & \\
\hline & 207 & 2094 & 080 & & 03 & 198 & 1969 & 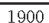 & \\
\hline
\end{tabular}

COBERTURA REL. $(\%)$

Especies características de la asociación Ladenbergio macrocarpae - Elaeagietum myrianthae

Ladenbergia macrocarpa Elaeagia mriantha

cordia nabescens

Nectandra globosa

Aniba robusta

Tapirira guianensis

\begin{tabular}{|cccc|}
\hline 0,8 & 0,4 & 0,6 & 2,8 \\
27,5 & & 6,7 & 2,0 \\
4 & 3,3 & & \\
1,2 & & 0,8 & 1,1 \\
& & 2,3 & 10,9 \\
1,3 & 6,1 & & \\
\hline
\end{tabular}

4,8

0,6

Especies características de la asociación Guettardo hirsutae - Hedyosmetum translucidi
Guettarda hirsuta
Miconia sp. 2 (CKA 123)
0,8

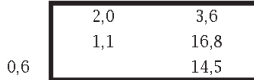

Especies características de la comunidad de Quercus humboldtii y Wettinia fascicularis

Wettinia fascicularis

Quercus humboldtii

Colombobalanus excels

Dictrocaryum lamarckiaman

0,8

Abarema killipil

0,6

3,5
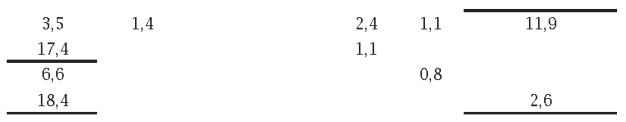

2,6

Especies características de la comunidad de Helicostylis tovarensis y Alfaroa williamsii

\begin{tabular}{|c|c|c|c|c|c|c|}
\hline Helicostylis tovarensis & 5,4 & 5,1 & & & 11,5 & 1,7 \\
\hline Alfaroa williamsii & 14 & & & 5,4 & 38,3 & 9,4 \\
\hline Spirotheca rhodostyla & 1 & & 4,3 & & 1,5 & 1,2 \\
\hline Pouteria baehniana & & & & & 6,0 & 2,5 \\
\hline Ocotea sp. 1 (CKA 99) & & 0,1 & & & 1,5 & 1,2 \\
\hline Palicourea garciae & 6,5 & & & & 5,7 & 2,1 \\
\hline Dugandiodendron colombianum & & & & 7,5 & 8,4 & 1 \\
\hline
\end{tabular}

Especies características de la comunidad de Baccharis nitida y Saurauia pulchra

Baccharis nitida

5,6

Saurauia pulchra

11,1

Rubus unticifolins

Especies características de la comunidad de Weinmannia pubescens y Clusia dixonii

Clusia dixonii

Rubiaceae sp. (YGO 122)

Aniba coto

Weimmamia pubescens

"Indeterminada sp. (N.C)

Escallonia paniculata

0,1

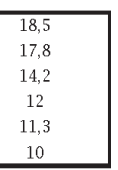


Otras especies presentes

Lozania mutisiana

Billia columbiana

Miconia dolichopoda

Miconia resima

Mollinedia tomentosa

Lauraceae sp. 4 (CKA 89)

Montanoa quadrangularis

Viburnum colombianum

Cinnamomum triplinerve

Rollinia sp. (CKA 186)

Ilex laurina

${ }^{*}$ Leon sp. (N.C)

Wettinia sp.

Mollinedia repanda

Viburnum cornifolium

Ocotea macropoda

Persea rigens

Beilschmiedia tovarensis

Nectandra hihua

Cinchona officinalis

Clethra fagifolia var. fagifolia

Faramea flavicans

Ocotea oblonga

Palicourea cuatrecasasii

Alchornea latifolia

Hedyosmum racemosum

Dunalia sp. (CKA 249)

Erythrina edulis

Piper lanceaefolium var. latifolium

*Indeterminada sp. (CKA 28)

*Indeterminada sp. 3 (N.C)

Meliaceae sp. (N.C)

Palicourea sp. 4 (CKA 29)

Persea subcordata

Austroeupatorium inulifolium

Piper aduncum

*Indeterminada sp. (CKA 225)

*Indeterminada sp. 2 (CKA 274)

Casearia mollis

Casearia sylvestris

Lauraceae sp. 5 (CKA 227)

Staphylacaceae sp. 1 (CKA 183)

Weinmannia magnifolia

*Indeterminada sp. (YGO 135)

*Indeterminada sp. (YGO 145)

Alchornea grandiflora

Prestoea carderi

Beilschmiedia pendula

Calophyllum brasiliense

Chrysochlamys colombiana

Drimys granadensis

Freziera karsteniana

Geissanthus bogotensis

Hesperomeles obtusifolia

Myrcianthes sp. (YGO 154)

Ocotea floribunda

Palicourea angustifolia

Panopsis suaveolens

Ruagea sp. 1 (YGO 19)

Solanum deflexiflorum
$\mathrm{L} 3 / 4,0 ; \mathrm{L} 4 / 2,3 ; \mathrm{L} 5 / 6,4$

$\mathrm{L} 3 / 5,0 ; \mathrm{L} 13 / 1,2 ; \mathrm{L} 2 / 9,2$

$\mathrm{L} 3 / 8,4 ; \mathrm{L} 13 / 0,3 ; \mathrm{L} 5 / 0,6$

$\mathrm{L} 1 / 2,9 ; \mathrm{L} 4 / 5,8 ; \mathrm{L} 2 / 10,2$

$\mathrm{L} 1 / 0,8 ; \mathrm{L} 4 / 0,6 ; \mathrm{L} 2 / 1,8$

$\mathrm{L} 13 / 2,0 ; \mathrm{L} 4 / 3,6 ; \mathrm{L} 5 / 3,0$

$\mathrm{L} 9 / 0,5 ; \mathrm{L} 5 / 1,3 ; \mathrm{L} 9 / 0,5$

$\mathrm{L} 1 / 0,1 ; \mathrm{L} 9 / 0,6 ; \mathrm{L} 9 / 0,6$

L3/28,7; L7/6,9

$\mathrm{L} 3 / 3,5 ; \mathrm{L} 7 / 4,8$

$\mathrm{L} 16 / 2,4 ; \mathrm{L} 10 / 0,8$

$\mathrm{L} 3 / 20,9 ; \mathrm{L} 5 / 3,0$

$\mathrm{L} 5 / 18,7 ; \mathrm{L} 7 / 12,4$

$\mathrm{L} 2 / 5,7 ; \mathrm{L} 5 / 4,6$

L2/3,2;L5/7,5

$\mathrm{L} 4 / 1,0 ; \mathrm{L} 10 / 1,0$

L1/2,6;L10/0,5

L13/1,5;L10/1,6

L13/1,8;L10/2,2

$\mathrm{L} 1 / 0,3 ; \mathrm{L} 2 / 6,0$

$\mathrm{L} 4 / 2,0 ; \mathrm{L} 2 / 0,8$

$\mathrm{L} 1 / 0,4 ; \mathrm{L} 2 / 3,9$

$\mathrm{L} 1 / 1,2 ; \mathrm{L} 2 / 3,2$

L1/1,8:L5/1,5

L13/2,0;L5/3,9

L5/4,0;L16/1,2

L9/2,2;L9/2,2

$\mathrm{L} 9 / 1,2 ; \mathrm{Lg} / 1,2$

L9/2,4;L9/2,4

L3/2,4

L3/4,8

L3/3,0

L3/4,0

L3/0,2

L11/18,7

L8/10,9

L10/1,6

L10/1,2

L10/1,0

L10/1,5

L10/0,8

$\mathrm{L} 7 / 2,4$

$\mathrm{L} 7 / 7,0$

L2/3,1

L2/1,3

$\mathrm{L} 2 / 13,1$

L2/0,1

L2/6,2

$\mathrm{L} 5 / 5,2$

$\mathrm{L} 2 / 4,2$

$\mathrm{L} 5 / 1,8$

$\mathrm{L} 2 / 6,1$

L2/7,9

$\mathrm{L} 2 / 4,0$

$\mathrm{L} 2 / 5,0$

L2/3,2

$\mathrm{L} 5 / 2,4$

L2/3,1

L2/1,3

L2/7,2
Symplocos flosfragrans $\quad \mathrm{L} 2 / 4,0$

Matudaea colombiana $\quad$ L10/5,3

Psychotria longirostris $\quad \mathrm{L} 10 / 1,0$

*Indeterminada sp. (YGO 397) L L11/0,2

Chromolaena odorata L11/9,2

Elephantopus sp. 1 (YGO 399) L11/0,2

Hyptis pseudosinuata $\quad \mathrm{L} 11 / 0,0$

Pilea rhombea $\quad \mathrm{L} 11 / 0,0$

Sida rhombifolia L11/0,9

Solanaceae sp. (N.C) L L12/1,2

Solanum subinerme $\quad \mathrm{L} 11 / 1,1$

Tibouchina ciliaris $\quad \mathrm{L} 11 / 0,0$

*Indeterminada sp. 1 (N.C) L16/3,0

Aiphanes cf. lindeniana $\quad$ L16/0,6

Aniba perutilis L16/6,2

Blakea fissicalyx $\quad \mathrm{L} 16 / 8,0$

Clethra sp. 2 (YGO 449) ～L16/0,6

Clusia flavida L16/2,7

Euphorbiaceae sp. 1 (YGO 446) L L $\quad$ L16/6,0

Pouteria torta $\quad \mathrm{L} 16 / 3,5$

Ternstroemnia macrocarpa $\quad$ L16/4,5

Tovomita weddelliana $\quad \mathrm{L} 16 / 1,0$

Vismia baccifera L8/6,1

*Indeterminada sp. (CKA 190) L7/9,8

Alchornea coelophylla $\quad$ L7/3,2

Alchornea glandulosa $\quad \mathrm{L} 7 / 1,5$

Asteraceae sp. 5 (CKA 187) L7/4,4

Billia columbiana $\quad \mathrm{L} 7 / 1,5$

Endlicheria formosa $\quad \mathrm{L} 7 / 4,0$

Endlicheria sp. 2 (YGO 320) L7/8,5

Eschweilera sessilis $\quad \mathrm{L} 7 / 2,5$

Ficus caldasiana $\quad \mathrm{L} 7 / 1,0$

Ficus subandina $\quad \mathrm{L} 7 / 4,0$

Inga setosa $\quad \mathrm{L} 7 / 0,9$

Matayba arborescens $\quad$ L7/2,5

Meriania huilensis $\quad \mathrm{L} 7 / 2,0$

Miconia theaezans $\quad \mathrm{L} 7 / 3,2$

Myrsine guianensis $\quad \mathrm{L} 7 / 5,5$

Oreopanax ruizii $\quad \mathrm{L} 7 / 1,2$

Ormosia tovarensis $\quad \mathrm{L} 7 / 1,6$

Palicourea sp. (CKA 191) L7/0,5

Palicourea sp. (CKA 191) L L7/0,5

Tocoyena costanensis $\quad \mathrm{L} 2 / 5,0$

Viburnum glabratum $\quad \mathrm{L} 2 / 3,2$

Vochysia megalantha $\quad \mathrm{L} 5 / 3,0$

Clusia discolor $\quad \mathrm{L} 4 / 0,8$

Cornus peruviana $\quad \mathrm{L} 1 / 8,4$

Cybianthus cuatrecasasii $\quad \mathrm{L} 1 / 0,8$

Guarea kunthiana $\quad \mathrm{L} 1 / 0,7$

Ormosia revoluta $\quad L 4 / 0,8$

Saurauia tomentosa $\quad \mathrm{L} 1 / 1,3$

Tibouchina sp. 1 (CKA 81) L L L $\quad$ L

Tulpinia occidentalis $\quad \mathrm{L} 1 / 1,8$

Weinmannia sorbifolia var. sclerophyla $\quad L 4 / 5,7$

Weinmannia subsessiliflora var. caquetana $\quad L 1 / 1,5$

Cybianthus spichigeri L13/0,6

Ficus popayanensis $\quad \mathrm{L} 13 / 2,5$

Piperaceae sp. (CKA 131) ～L13/0,6

Viburnum lehmannii $\quad \mathrm{L} 13 / 1,1$

*Indeterminada sp. (CKA 300) L14/0,4

Pouteria argenteum spp auratum ～L14/6,0 


\begin{tabular}{|c|c|c|c|c|c|c|}
\hline \multirow{3}{*}{ Especies } & \multirow{3}{*}{ Especies } & \multicolumn{4}{|c|}{ Asociaciones } & \multirow{36}{*}{$\begin{array}{l}\text { Electiva } \\
\text { Exclusiva }\end{array}$} \\
\hline & & \multicolumn{2}{|c|}{$\begin{array}{c}\text { Ladenbergio } \\
\text { macrocarpae - } \\
\text { Elaeagietum } \\
\text { myrianthae }\end{array}$} & \multicolumn{2}{|c|}{$\begin{array}{l}\text { Guettardo } \\
\text { hirsutae - } \\
\text { Hedyosmetum } \\
\text { translucidi }\end{array}$} & \\
\hline & & PRE & COBER & PRE & COBER & \\
\hline 1 & Endlicheria griseo-sericea & III & 1 & III & 1 & \\
\hline 2 & Cyathea sp. 1 (YGO 45) & V & 1 & III & + & \\
\hline 3 & Morus insignis & I & 1 & III & 1 & \\
\hline 4 & Nectandra discolor & I & 1 & III & 1 & \\
\hline 5 & Cecropia angustifolia & III & 1 & III & + & \\
\hline 6 & Ladenbergia macrocarpa & IV & 1 & III & 1 & \\
\hline 7 & Miconia sp. 2 (CKA 123) & I & + & V & 1 & \\
\hline 8 & Hedyosmum translucidum & I & + & III & 2 & \\
\hline 9 & Spirotheca rhodostyla & I & + & III & 1 & \\
\hline 10 & Baccharis nitida & I & 1 & III & 1 & \\
\hline 11 & Lozania mutisiana & ॥ & 1 & III & 1 & \\
\hline 12 & Miconia dolichopoda & II & 1 & III & + & \\
\hline 13 & Lauraceae sp. 4 (CKA 89) & II & 1 & III & 1 & \\
\hline 14 & Montanoa quadrangularis & I & + & III & 1 & \\
\hline 15 & ${ }^{*}$ Leon sp. (N.C) & I & 2 & III & 1 & \\
\hline 16 & Palicourea cuatrecasasii & I & 1 & III & 1 & \\
\hline 17 & Alchornea latifolia & I & 1 & III & 1 & \\
\hline 18 & Elaeagia myriantha & III & 2 & & & \\
\hline 19 & Hedyosmum cuatrecazanum & III & 1 & & & \\
\hline 20 & Nectandra globosa & III & + & & & \\
\hline 21 & Vismia baccifera & $\|$ & 1 & & & \\
\hline 22 & Lauraceae sp. (N.C) & $\|$ & 1 & & & \\
\hline 23 & Tapirira guianensis & ॥ & 1 & & & \\
\hline 24 & Helicostylis tovarensis & ॥ & 1 & & & \\
\hline 25 & Saurauia vulchra & ॥ & 1 & & & \\
\hline 26 & Aniba robusta & $\|$ & 1 & & & \\
\hline 27 & Billia columbiana & ॥ & 1 & & & \\
\hline 28 & Miconia resima & ॥ & 1 & & & \\
\hline 29 & Viburnum colombianum & $\|$ & + & & & \\
\hline 30 & Cinnamomum triplinerve & I & 3 & & & \\
\hline 31 & Alfaroa williamsii & I & 2 & & & \\
\hline 32 & Colombobalanus excelsa & 1 & 1 & & & \\
\hline 33 & Palicourea garciae & I & 1 & & & \\
\hline
\end{tabular}




\begin{tabular}{|c|c|c|c|c|c|}
\hline \multirow{3}{*}{\multicolumn{2}{|c|}{ Especies }} & \multicolumn{4}{|c|}{ Asociaciones } \\
\hline & & \multicolumn{2}{|c|}{$\begin{array}{l}\text { Ladenbergio } \\
\text { macrocarpae - } \\
\text { Elaeagietum } \\
\text { myrianthae }\end{array}$} & \multicolumn{2}{|c|}{$\begin{array}{c}\text { Guettardo } \\
\text { hirsutae - } \\
\text { Hedyosmetum } \\
\text { translucidi }\end{array}$} \\
\hline & & PRE & COBER & PRE & COBER \\
\hline 34 & Rollinia sp. (CKA 186) & I & 1 & & \\
\hline 35 & Persea rigens & I & 1 & & \\
\hline 36 & Beilschmiedia tovarensis & I & 1 & & \\
\hline 37 & Nectandra hihua & I & 1 & & \\
\hline 38 & Dunalia sp. (CKA 249) & I & 1 & & \\
\hline 39 & Erythrina edulis & I & 1 & & \\
\hline 40 & Piper lanceaefolium var. Iatifolium & I & 1 & & \\
\hline 41 & Clethra fagifolia var. fagifolia & I & 1 & & \\
\hline 42 & *Indeterminada sp. (CKA 28) & I & 1 & & \\
\hline 43 & *Indeterminada sp. 3 (N.C) & I & 1 & & \\
\hline 44 & Ocotea oblonga & I & 1 & & \\
\hline 45 & Meliaceae sp. (N.C) & I & 1 & & \\
\hline 46 & Palicourea sp. 4 (CKA 29) & I & 1 & & \\
\hline 47 & Cornus peruviana & I & 1 & & \\
\hline 48 & Saurauia tomentosa & I & 1 & & \\
\hline 49 & Turpinia occidentalis & I & 1 & & \\
\hline 50 & Weinmannia sorbifolia var. sclerophylla & I & 1 & & \\
\hline 51 & Weinmannia subsessiliflora var. caquetana & I & 1 & & \\
\hline 52 & Ficus popayanensis & 1 & 1 & & \\
\hline 53 & Viburnum lehmannii & I & 1 & & \\
\hline 54 & Prunus opaca & I & 1 & & \\
\hline 55 & Weinmannia pubescens & I & 1 & & \\
\hline 56 & *Indeterminada sp. (N.C) & I & 1 & & \\
\hline 57 & Ocotea sp. 1 (CKA 99) & I & + & & \\
\hline 58 & Ocotea macropoda & I & + & & \\
\hline 59 & Persea subcordata & I & + & & \\
\hline 60 & Clusia discolor & I & + & & \\
\hline 61 & Cybianthus cuatrecasasii & 1 & + & & \\
\hline 62 & Guarea kunthiana & I & + & & \\
\hline 63 & Ormosia revoluta & I & + & & \\
\hline 64 & Tibouchina sp. 1 (CKA 81) & I & + & & \\
\hline 65 & Cybianthus spichigeri & I & + & & \\
\hline 66 & Piperaceae sp. (CKA 131) & 1 & + & & \\
\hline
\end{tabular}

Electiva

Exclusiva 


\begin{tabular}{|c|l|c|c|c|c|}
\hline \multirow{2}{*}{\multicolumn{2}{|c|}{ Especies }} & \multicolumn{3}{|c|}{ Asociaciones } \\
\cline { 3 - 6 } & \multicolumn{2}{|c|}{$\begin{array}{c}\text { Ladenbergio } \\
\text { macrocarpae - } \\
\text { Elaeagietum } \\
\text { myrianthae }\end{array}$} & $\begin{array}{c}\text { Guettardo } \\
\text { hirsutae - } \\
\text { Hedyosmetum } \\
\text { translucidi }\end{array}$ \\
\cline { 3 - 6 } & PRE & COBER & PRE & COBER \\
\hline 67 & Rudgea sp. 1 (YGO 5) & I & + & & \\
\hline 68 & Faramea flavicans & I & + & & \\
\hline 69 & Cinchona officinalis & I & + & & \\
\hline 70 & Mollinedia tomentosa & II & + & & \\
\hline 71 & Guettarda hirsuta & & & V & 1 \\
\hline 72 & Wettinia sp. & & & III & 2 \\
\hline 73 & Hediosmum racemosum & & & III & 1 \\
\hline 74 & Calophyllum brasiliense & & & III & 1 \\
\hline 75 & Drimys granadensis & & & III & 1 \\
\hline 76 & Palicourea angustifolia & & & III & 1 \\
\hline 77 & Vochysia megalantha & & & III & 1 \\
\hline 78 & Mollinedia repanda & & III & 1 \\
\hline 79 & Viburnum comifolium & & III & 1 \\
\hline
\end{tabular}

Electiva

Exclusiva 
Yitsully González-O / Ana Coca-A / Edgard Ernesto Cantillo-H

\begin{tabular}{|c|c|c|c|c|c|c|c|c|c|}
\hline \multirow{3}{*}{\multicolumn{2}{|c|}{ Especies }} & \multicolumn{8}{|c|}{ Comunidades } \\
\hline & & \multicolumn{2}{|c|}{$\begin{array}{l}\text { Quercus } \\
\text { humboldtii } \\
\text { Wettinia } \\
\text { fascicularis }\end{array}$} & \multicolumn{2}{|c|}{$\begin{array}{c}\text { Helicostylis } \\
\text { tovarensis y } \\
\text { Alfaroa } \\
\text { williamsii }\end{array}$} & \multicolumn{2}{|c|}{$\begin{array}{c}\text { Baccharis } \\
\text { nitida y } \\
\text { Saurauia } \\
\text { pulchra }\end{array}$} & \multicolumn{2}{|c|}{$\begin{array}{l}\text { Weinmmania } \\
\text { pubescens y } \\
\text { Clusia } \\
\text { dixonii }\end{array}$} \\
\hline & & PRE & COBER & PRE & COBER & PRE & COBER & PRE & COBER \\
\hline 1 & Endlicheria griseo-sericea & ॥ & 1 & V & 1 & II & + & $\mathrm{V}$ & 1 \\
\hline 2 & Alfaroa williamsii & $\|$ & 1 & V & 2 & II & 1 & & \\
\hline 3 & Hyeronima huilensis & $\|$ & + & III & 1 & & & V & 1 \\
\hline 4 & Cyathea sp. 1 (YGO 45) & & & V & 1 & III & 1 & V & 2 \\
\hline 5 & Cecropia angustifolia & & & III & 2 & II & 1 & & \\
\hline 6 & Heliocarpus americanus & & & III & 1 & ॥ & + & & \\
\hline 7 & Quercus humboldtii & V & 3 & III & + & & & & \\
\hline 8 & Dictyocaryum lamarckianum & V & 1 & III & 1 & & & & \\
\hline 9 & Dugandiodendron colombianum & $\|$ & 1 & V & 1 & & & & \\
\hline 10 & Aniba coto & ॥ & 1 & & & & & V & 2 \\
\hline 11 & Pouteria baehniana & & & V & 1 & & & V & 1 \\
\hline 12 & Prunus opaca & & & III & 2 & & & V & + \\
\hline 13 & Hedyosmun cuatrecazanum & & & III & 2 & & & V & 1 \\
\hline 14 & Billia collumbiana & & & III & 1 & & & V & 1 \\
\hline 15 & Ilex laurina & II & 1 & III & + & & & & \\
\hline 16 & Wettinia fascicularis & V & 3 & & & & & & \\
\hline 17 & Colombobalanus excelsa & V & 2 & & & & & & \\
\hline 18 & Abarema killipii & IV & 1 & & & & & & \\
\hline 19 & Hedyosmun racemosum & ॥ & 1 & & & & & & \\
\hline 20 & *Indeterminada sp. 1 (N.C) & $\|$ & 1 & & & & & & \\
\hline 21 & Aniba perutilis & ॥ & 1 & & & & & & \\
\hline 22 & Blakea fissicalyx & ॥ & 1 & & & & & & \\
\hline 23 & Clusia flavida & $\|$ & 1 & & & & & & \\
\hline 24 & Euphorbiaceae sp. 1 (YGO 446) & $\|$ & 1 & & & & & & \\
\hline 25 & Pouteria torta & $\|$ & 1 & & & & & & \\
\hline 26 & Ternstroemnia macrocarpa & & & $\|$ & 1 & & & & \\
\hline 27 & Pouteria argenteun spp auratu & & & $\|$ & 1 & & & & \\
\hline 28 & Tapirira guianensis & & & ॥ & + & & & & \\
\hline 29 & Aiphanes linearis & & & $\|$ & + & & & & \\
\hline 30 & Clethra sp. 2 (YGO 449) & & & ॥ & + & & & & \\
\hline 31 & Tovomita weddelliana & & & ॥ & + & & & & \\
\hline 32 & *Indeterminada sp. (CKA 300) & & & $\|$ & + & & & & \\
\hline 33 & Helicostylis tovarensis & & & V & + & & & & \\
\hline
\end{tabular}

Electiva

Exclusiva 


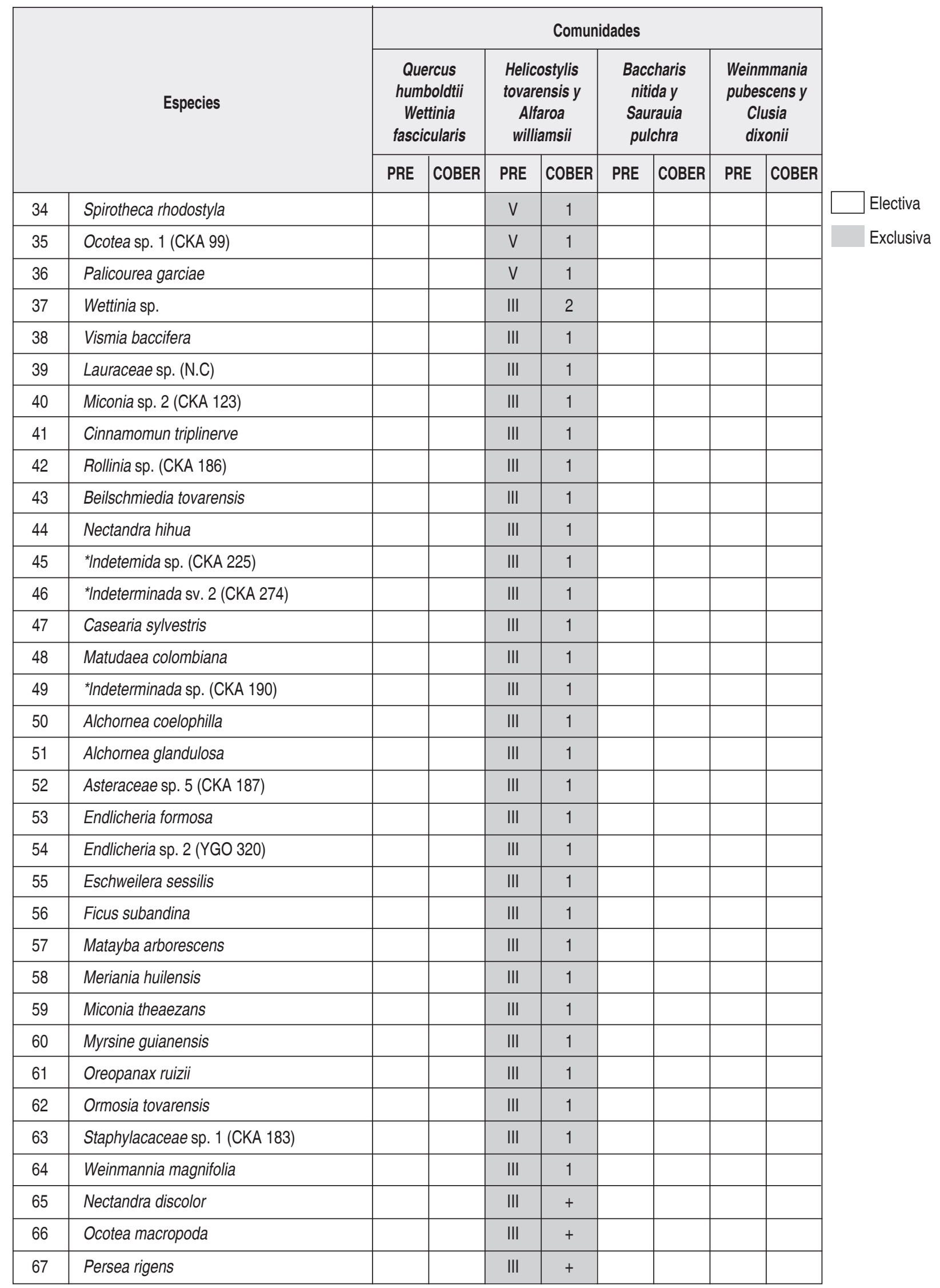




\begin{tabular}{|c|c|c|c|c|c|c|c|}
\hline \multirow{3}{*}{\multicolumn{2}{|c|}{ Especies }} & \multicolumn{6}{|c|}{ Comunidades } \\
\hline & & \multicolumn{2}{|c|}{$\begin{array}{c}\text { Helicostylis } \\
\text { tovarensis y } \\
\text { Alfaroa } \\
\text { williamsii }\end{array}$} & \multicolumn{2}{|c|}{$\begin{array}{c}\text { Baccharis } \\
\text { nitida y } \\
\text { Saurauia } \\
\text { pulchra }\end{array}$} & \multicolumn{2}{|c|}{$\begin{array}{c}\text { Weinmannia } \\
\text { pubescens y } \\
\text { Clusia } \\
\text { dixonii }\end{array}$} \\
\hline & & PRE & COBER & PRE & COBER & PRE & COBER \\
\hline 68 & Casearia mollis & III & + & & & & \\
\hline 69 & Lauraceae sp. 5 (CKA 227) & III & + & & & & \\
\hline 70 & Psychotria longirostris & III & + & & & & \\
\hline 71 & Ficus caldasiana & III & + & & & & \\
\hline 72 & Inga setosa & III & + & & & & \\
\hline 73 & Palicourea sp. (CKA 191) & III & + & & & & \\
\hline 74 & Baccharis nitida & & & V & 1 & & \\
\hline 75 & Saurauia pulchra & & & IV & 1 & & \\
\hline 76 & *Indeterminada sp. (N.C) & & & III & 1 & & \\
\hline 77 & Rubus urticifolius & & & ॥ & 3 & & \\
\hline 78 & Austroeupatorium inulifolium & & & $\|$ & 2 & & \\
\hline 79 & Piper aduncum & & & $\|$ & 2 & & \\
\hline 80 & Morus insignis & & & II & 1 & & \\
\hline 81 & Guettarda hirsuta & & & $\|$ & 1 & & \\
\hline 82 & Dunalia sp. (CKA 249) & & & II & 1 & & \\
\hline 83 & Erythrina edulis & & & ॥ & 1 & & \\
\hline 84 & Piper lanceaefolium var. latifolium & & & ॥ & 1 & & \\
\hline 85 & Chromolaena odorata & & & $\|$ & 1 & & \\
\hline 86 & Solanaceae sp. (N.C) & & & $\|$ & 1 & & \\
\hline 87 & Solanum subinerme & & & II & 1 & & \\
\hline 88 & Vismia baccifera & & & II & 1 & & \\
\hline 89 & Cordia rubescens & & & ॥ & + & & \\
\hline 90 & Montanoa quadrangularis & & & II & + & & \\
\hline 91 & Viburnum colombianum & & & II & + & & \\
\hline 92 & *Indeterminada sp. (YGO 397) & & & $\|$ & + & & \\
\hline 93 & Elephantopus sp. 1 (YGO 399) & & & II & + & & \\
\hline 94 & Hyptis pseudosinuata & & & ॥ & + & & \\
\hline 95 & Pilea rhombea & & & II & + & & \\
\hline 96 & Sida rhombifolia & & & ॥ & + & & \\
\hline 97 & Tibouchina ciliaris & & & II & + & & \\
\hline 98 & Rudgea sp. 1 (YGO 5) & & & & & V & + \\
\hline 99 & Elaeagia myriantha & & & & & V & 2 \\
\hline 100 & Nectandra globosa & & & & & V & 1 \\
\hline
\end{tabular}

Electiva

Exclusiva 
Estructura y composición florística de la vegetación del corredor biológico PNN Puracé y Cueva de los Guácharos

\begin{tabular}{|c|c|c|c|c|c|c|c|}
\hline \multirow{3}{*}{\multicolumn{2}{|c|}{ Especies }} & \multicolumn{6}{|c|}{ Comunidades } \\
\hline & & \multicolumn{2}{|c|}{$\begin{array}{c}\text { Helicostylis } \\
\text { tovarensis y } \\
\text { Alfaroa } \\
\text { williamsii }\end{array}$} & \multicolumn{2}{|c|}{$\begin{array}{c}\text { Baccharis } \\
\text { nitida y } \\
\text { Saurauia } \\
\text { pulchra }\end{array}$} & \multicolumn{2}{|c|}{$\begin{array}{c}\text { Weinmannia } \\
\text { pubescens y } \\
\text { Clusia } \\
\text { dixonii }\end{array}$} \\
\hline & & PRE & COBER & PRE & COBER & PRE & COBER \\
\hline 101 & Aniba robusta & & & & & V & 2 \\
\hline 102 & Weinmannia pubescens & & & & & V & 2 \\
\hline 103 & *Indeterminada sp. (N.C) & & & & & V & 2 \\
\hline 104 & Miconia resima & & & & & V & 2 \\
\hline 105 & Mollinedia tomentosa & & & & & V & 1 \\
\hline 106 & Mollinedia repanda & & & & & V & 1 \\
\hline 107 & Viburnum cornifolium & & & & & V & 1 \\
\hline 108 & Cinchona officinalis & & & & & V & 1 \\
\hline 109 & Clethra fagifolia var. fagifolia & & & & & V & + \\
\hline 110 & Faramea flavicans & & & & & V & 1 \\
\hline 111 & Ocotea oblonga & & & & & V & 1 \\
\hline 112 & Clusia dixonii & & & & & V & 2 \\
\hline 113 & Rubiaceae sp. (YGO 122) & & & & & V & 2 \\
\hline 114 & Alchornea grandiflora & & & & & V & 2 \\
\hline 115 & Escallonia paniculata & & & & & V & 1 \\
\hline 116 & *Indeterminada sp. (YGO 135) & & & & & V & 1 \\
\hline 117 & *Indeterminada sp. (YGO 145) & & & & & V & 1 \\
\hline 118 & Beilschmiedia pendula & & & & & V & 1 \\
\hline 119 & Chrysochlamys colombiana & & & & & V & 1 \\
\hline 120 & Freziera karsteniana & & & & & V & 1 \\
\hline 121 & Geissanthus bogotensis & & & & & V & 1 \\
\hline 122 & Hesperomeles obtusifolia & & & & & V & 1 \\
\hline 123 & Myrcianthes sp. (YGO 154) & & & & & V & 1 \\
\hline 124 & Ocotea floribunda & & & & & V & 1 \\
\hline 125 & Panopsis suaveolens & & & & & V & 1 \\
\hline 126 & Ruagea sp. 1 (YGO 19) & & & & & V & 1 \\
\hline 127 & Solanum deflexiflorum & & & & & V & 1 \\
\hline 128 & Symplocos flosfragrans & & & & & V & 1 \\
\hline 129 & Tocoyena costanensis & & & & & V & 1 \\
\hline 130 & Viburnum glabratum & & & & & V & 1 \\
\hline 131 & Prestoea carderi & & & & & $\mathrm{V}$ & + \\
\hline
\end{tabular}

